\title{
ARTICLE
}

\section{A Novel hydrophilic heterogeneous cobalt catalyst for fluoride- free Hiyama, Suzuki, Heck and Hirao cross-coupling reactions in water}

Received 00th January 20xx, Accepted 00th January 20xx DOI: $10.1039 / \times 0 \times x 00000 x$

\author{
Sara Sobhani, ${ }^{* a}$ Hadis Hosseini Moghadam, ${ }^{a}$ Jørgen Skibsted ${ }^{\mathrm{b}}$ and José Miguel Sansano ${ }^{\mathrm{c}}$
}

\begin{abstract}
A novel hydrophilic heterogeneous cobalt catalyst denoted as mTEG-CS-Co-Schiff-base was prepared successfully. This newly synthesized catalyst was characterized by different methods such as XRD, FE-SEM, TEM, TGA, FT-IR, ${ }^{13} \mathrm{C}\left\{{ }^{1} \mathrm{H}\right\}$ CP/MAS NMR, XPS and ICP analysis. The catalyst displayed excellent activity for the palladium and fluoride-free Hiyama, Suzuki, Heck and Hirao reactions of various aryl iodides, bromides and chlorides (the most challenging aryl halides which are cheaper and more widely available than aryl iodides and bromides) in water. The presence of triethylene glycol tags with hydrophilic character on the Co-complex supported on chitosan provides dispersion of the catalyst particles in water, which leads to higher catalytic performance and also facile catalyst recovery by successive extraction. It was reused for at least six successive runs without any discernible decrease in its catalytic activity and remarkable changes in catalyst structure. Using water as a green solvent without requiring any additive or organic solvent, using low cost and abundant cobalt catalyst instead of expensive Pd catalysts, catalyst recovery and scalability make this method favorable from the environmental and economic points of view for the $\mathrm{C}-\mathrm{C}$ and $\mathrm{C}\left(\mathrm{sp}^{2}\right)-\mathrm{P}$ coupling reactions. Notably, this is the first report on the application of cobalt catalyst in Hiyama reactions.
\end{abstract}

\section{Introduction}

Carbon-carbon and carbon-phosphorus coupling reactions as a powerful synthetic tool and major area in multiple organic transformations have recently been one of the most intensively studied in organic synthesis and have been applied to many areas, including the synthesis of natural products, drugs and fine chemicals. ${ }^{1}$ The traditional catalysts for cross-coupling reactions are homogeneous palladium complexes. Application of palladium complexes has some limitations such as toxicity, cost, nonreusability and sensitivity to air. ${ }^{2}$ These problems can be largely overcome by carrying out the reactions using heterogeneous-based catalysts, and/or using other transition metals such as nickel, ${ }^{3}$ copper, ${ }^{4}$ iron $^{5}$ and cobalt. ${ }^{6}$ However, in spite of low cost, nontoxicity and availability of cobalt catalysts, the applicability of this metal catalyst in coupling reactions compared to the above

\footnotetext{
a. Address: Department of Chemistry, College of Sciences, University of Birjand, Birjand, Iran, email: ssobhani@birjand.ac.ir, sobhanisara@yahoo.com.

b. Department of Chemistry and Interdisciplinary Nanoscience Centre (iNANO), Aarhus University, Langelandsgade 140, DK-8000 Aarhus C, Denmark.

c. José Miguel Sansano

Departamento de Qu'ımica Org'anica, Facultad de Ciencias, Centro de Innovacion en Qu'Imica Avanzada (ORFEO-CINQA) and Instituto de S'intesis Org'anica (ISO), Universidad de Alicante, Apdo. 99, 03080-Alicante, Spain.
}

mentioned metal catalysts is rare in the literature. ${ }^{7}$

A variety of inorganic and organic materials have been already used for supporting different metal catalysts to produce heterogeneous catalysts. ${ }^{8}$ Within these solid supports, biopolymer supporting materials such as chitosan (CS) have gained much attention due to the unique characteristics of the biomaterials; which are nontoxic, biodegradable, environmentally friendly, renewable and abundant. ${ }^{9}$ CS is a major naturally occurring biopolymer, which is produced by deacetylation of chitin, the key constituents of the shells of crab and shrimp. ${ }^{10}$ It exhibits high affinity for metal ions due to the amine and hydroxyl functional groups on its chain. These characteristics have made chitosan as a desirable material in removal of radioactive elements, waste water treatment, textile production, medicine, agriculture, cosmetics, photography, biotechnology, food and nutrition. ${ }^{11}$ More importantly, the presence of these groups provides the possibility of the chitosan modification to have new properties or to prepare the heterogeneous catalysts. ${ }^{12}$ For example, by amine modification of CS, CS-Schiff-base-cobalt complexes were synthesized and used as heterogeneous catalysts in organic reactons. ${ }^{13}$ Notably, chitosan is only soluble in acidic aqueous media and is insoluble in basic aqueous media, which is important for some reactions such as cross-coupling reactions. Remarkably, from environmental and economic perspectives, the interest in catalytic processes by recyclable metal-based catalysts in aqueous media is dramatically increased. ${ }^{14}$ Along this line and in continuing of our 
efforts on the introduction of new heterogeneous catalysts for using in aqueous media, ${ }^{15}$ herein, in this paper, a new hydrophilic heterogeneous cobalt catalyst of chitosan (mTEG-CS-Co-Schiff-base, Scheme 1) was synthesized by the modification of both amine and hydroxyl functional groups on the CS chain. This newly synthesized catalyst was characterized by different methods such as XRD, FESEM, TEM, TGA, FT-IR, ${ }^{13} \mathrm{C}\left\{{ }^{1} \mathrm{H}\right\} \mathrm{CP} / \mathrm{MAS}$ NMR, XPS and ICP analysis and used as a heterogeneous catalyst in some $\mathrm{C}-\mathrm{C}$ and $\mathrm{C}\left(\mathrm{sp}^{2}\right)-\mathrm{P}$ cross-coupling reactions such as Hiyama, Suzuki, Heck and Hirao reactions.

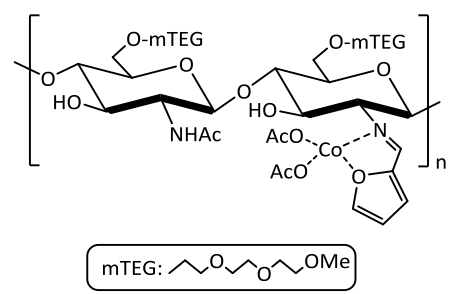

Scheme 1. mTEG-CS-Co-Schiff-base

\section{Result and discussion}

The catalyst was synthesized by the method outlined in Scheme 2. As shown in Scheme 2, at first the amino groups on chitosan chains were reacted with furfural to form CS-Schiff-base. Further modification of hydroxyl group of CS-Schiff-base with monomethoxytriethylene glycol (mTEG) as a phase transfer functional group, followed by the reaction with cobalt acetate produced mTEGCS-Co-Schiff-base.

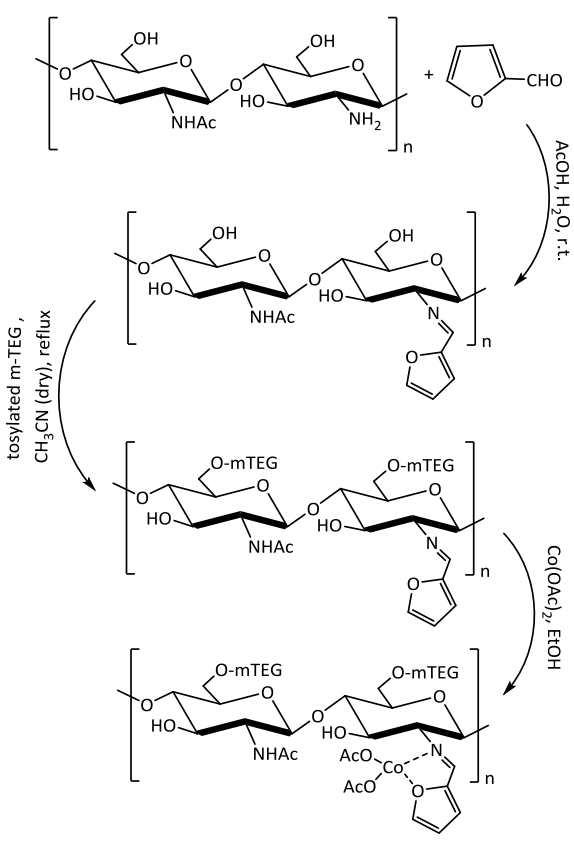

Scheme 2. Preparation of mTEG-CS-Co-Schiff-base

X-ray diffraction (XRD) pattern of mTEG-CS-Co-Schiff-base, mTEGCS-Schiff-base and chitosan are displayed in Figure 1. CS monomers have strong intermolecular hydrogen bonding and so CS usually presents more crystalline character than other carbohydrates. In the XRD pattern of CS two characteristic peaks at $2 \theta=10$ and $21^{\circ}$ were observed. Evaluation of the XRD pattern of mTEG-CS-Schiffbase and mTEG-CS-Co-Schiff-base, showed peaks decreasing and peak broadening. It should be related to the lowering of the amount of free amino groups during the condensation with aldehydes. The condensation led to the deformation of hydrogen bonds and lowered the crystallinity of chitosan.

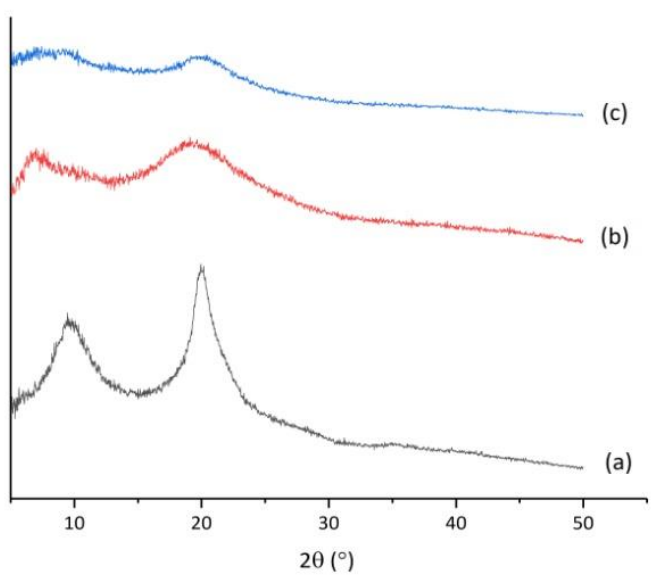

Figure 1. XRD pattern of a) CS, b) mTEG-CS-Schiff-base and c) mTEG-CS-Co-Schiff-base

The field emission scanning electron microscopy (FE-SEM) and transmission electron microscopy (TEM) images of mTEG-CS-CoSchiff-base are presented in Figure 2. The roughness observed on the surface of mTEG-CS-Co-Schiff-base, demonstrated the chemical modification of CS surface (Figure $2 a$ and $2 b$ ). The average particle size of cobalt species was $12 \mathrm{~nm}$ based on TEM image (Figure 2c and $2 \mathrm{~d}$ ).
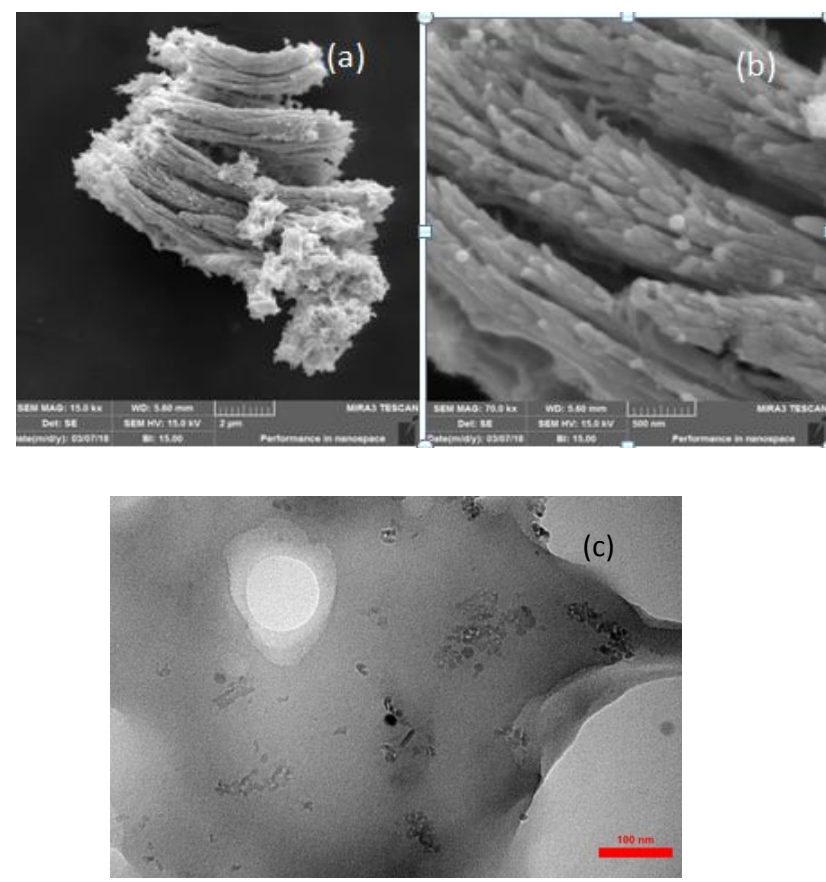


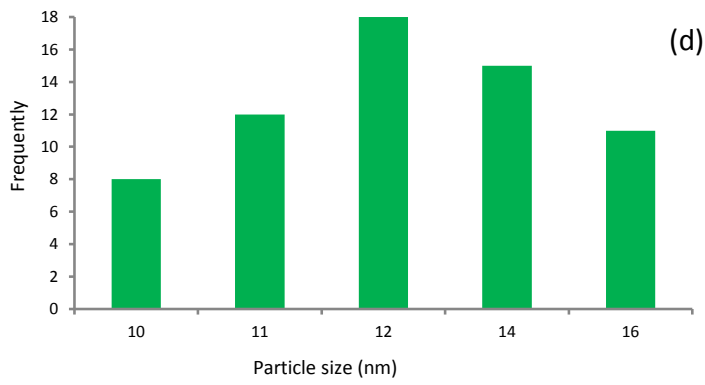

Figure 2. a, b) FE-SEM images, c) TEM image and d) particle size distributions of Co in mTEG-CS-Co-Schiff-base

The thermogravimetric analysis (TGA) of mTEG-CS-Schiff-base is shown in Figure 3. The TG analysis illustrates two mass loss stages. The initial mass loss ( 6.8\%) at around $100{ }^{\circ} \mathrm{C}$ is attributed to the evaporation of adsorbed water molecules. A total of $71.8 \%$ weight loss in the second stage is due to the decomposition of polysaccharide chain and also Schiff-base units. The amount of cobalt in one gram of the catalyst was $0.58 \mathrm{mmol}$, which was determined by ICP technique.

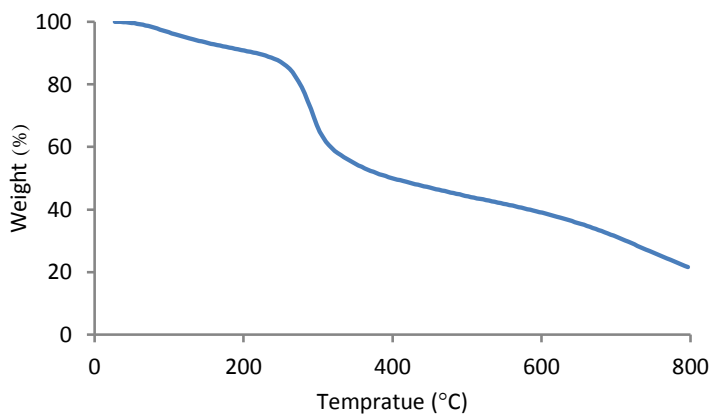

Figure 3. TG curve of mTEG-CS-Schiff-base

The Fourier-transform infrared (FT-IR) spectra of CS, CS-Schiff-base and mTEG-CS-Co-Schiff-base are shown in Figure 4. A comparison of FT-IR spectra of CS and CS-Schiff-base, indicates the absence of bending mode of $-\mathrm{NH}_{2}$ group at $1655 \mathrm{~cm}^{-1}$ and presence of two additional bands at 1649 and $1562 \mathrm{~cm}^{-1}$ in the FT-IR spectrum of CSSchiff base. These two new peaks are assigned to the stretching modes of imine $(\mathrm{C}=\mathrm{N})$ and $\mathrm{C}=\mathrm{C}$ groups, respectively. In the FT-IR spectrum of mTEG-CS-Co-Schiff-base, the shifting $\left(\sim 7 \mathrm{~cm}^{-1}\right)$ of stretching vibration of $\mathrm{C}=\mathrm{N}$ groups to lower wave number confirms the coordination of Co (II) metal ions to the nitrogen atoms of the Schiff base. The appearance of the band at $1114 \mathrm{~cm}^{-1}$ could be attributed to the C-O of TEG.

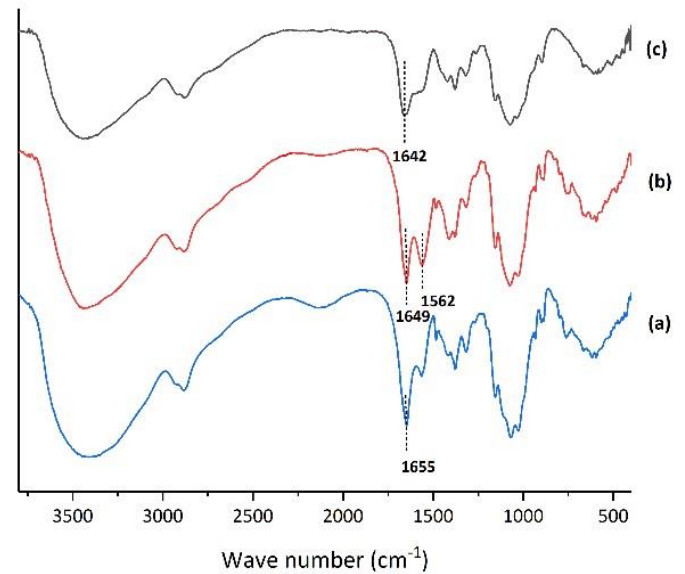

Figure 4. FT-IR spectra of a) CS, b) CS-Schiff base and c) mTEG-CSCo-Schiff-base

Solid-state nuclear magnetic resonance $\left[{ }^{13} \mathrm{C}\left\{{ }^{1} \mathrm{H}\right\} \quad \mathrm{CP} / \mathrm{MAS}\right.$ NMR] spectra of CS and the MTEG-CS-Co-Schiff-base are shown in Figure 5. In the spectrum of CS (Figure 5a), the resonances at around 24, 84,106 and $174 \mathrm{ppm}$ can be assigned to $C_{8}, C_{3}, C_{1}$ and $C_{7}$, respectively. The broad peaks at around $60 \mathrm{ppm}$ are attributed to $C_{2}, C_{2}$ and $C_{6}$, where at least two peaks are resolved at $58.1 \mathrm{ppm}$ and $60.9 \mathrm{ppm}$. The tallest peak at $75.7 \mathrm{ppm}$ is ascribed to $C_{4}$ and $C_{5}$. Furan ring with characteristic peaks at 126.6, 129.7, 142.8, 151.3, and $156.5 \mathrm{ppm}$ are observed in the ${ }^{13} \mathrm{C}\left\{{ }^{1} \mathrm{H}\right\} \mathrm{CP} /$ MAS NMR spectrum of mTEG-CS-Co-Schiff-base (Scheme 1, Figure 5b), which indicates that the furfural is linked with CS through the Schiff-base reaction. Furthermore, resonances at $49.9 \mathrm{ppm}\left(-\mathrm{OCH}_{3}\right)$ and $71.8 \mathrm{ppm}$ ($\mathrm{OCH}_{2} \mathrm{CH}_{2} \mathrm{O}-$ ) overlap with the $\mathrm{C}_{4}$ and $\mathrm{C}_{5}$ sites of the chitosan ring. This confirms the presence of MTEG in the MTEG-CS-Co-Schiff base. 


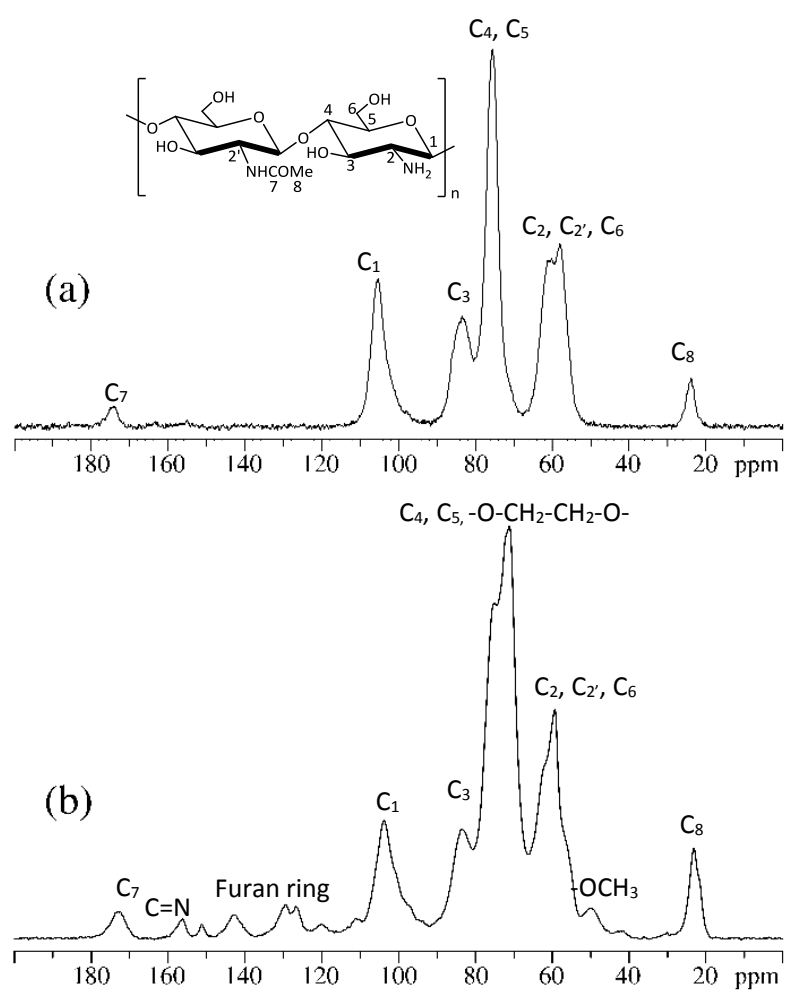

Figure 5. ${ }^{13} \mathrm{C}\left\{{ }^{1} \mathrm{H}\right\} \mathrm{CP} / \mathrm{MAS}$ NMR spectra of a) $\mathrm{CS}$ and b) mTEG-CS-Co-Schiffbase

The catalyst was also analyzed by XPS spectroscopy (Figure 6). The observed characteristic peaks in the XPS elemental survey are attributed to carbon ( $C 1 \mathrm{~s}$ ), nitrogen ( $N 1 \mathrm{~s}$ ), oxygen ( $\mathrm{O} 1 \mathrm{~s}$ ) and cobalt (Figure 6a). ${ }^{16}$ The $\mathrm{C}$ 1s spectrum (Figure $6 \mathrm{~b}$ ) showed binding energies at 284.2 ( $\mathrm{C}-\mathrm{C}$ and $\mathrm{C}-\mathrm{H}), 285.6(-\mathrm{C}=\mathrm{N}-), 286.8(\mathrm{C}-\mathrm{N}$ and $\mathrm{C}-\mathrm{OH})$ and $288.4 \mathrm{eV}$ (-C-O-C- and N-C=O). ${ }^{17}$ Furthermore, high resolution XPS results of $\mathrm{N} 1 \mathrm{~s}$ region confirmed the presence of $-\mathrm{N}-\mathrm{H}$ and imine ($\mathrm{N}=\mathrm{C}-)$ by revealing two peaks at 398.5 and $400.0 \mathrm{eV}$, respectively (Figure 6c). ${ }^{17}$ Three distinct peaks at 530.8, 532.2 and $533.6 \mathrm{eV}$ in the $\mathrm{O} 1 \mathrm{~s}$ spectrum (Figure $6 \mathrm{~d}$ ) represented the incorporation of Co-O, $\mathrm{C}=\mathrm{O}$ and $\mathrm{C}-0 .{ }^{16,17}$ Spectrum of cobalt matches well with the reported binding energy values of cobalt signals for immobilized Co-Schiffbase complexes (Figure 6e). ${ }^{18}$ The typical peaks at 781.1 and 796.7 $\mathrm{eV}$ for $2 \mathrm{p}_{3 / 2}$ and $2 \mathrm{p}_{1 / 2}$, respectively, indicate the presence of $\mathrm{Co}^{2+}$. Cobalt nanospecies which are observed in the TEM image (Figure $2 c$ ), might be cobalt acetate that are adsorbed on the surface of oxygenrich mTEG-CS-Co-Schiff-base catalyst. The peaks of adsorbed cobalt acetate overlapped with those of Co-complex in the Co-XPS spectrum at 783.1, 786.5, 798.7 and $802.4 \mathrm{eV} .{ }^{18}$
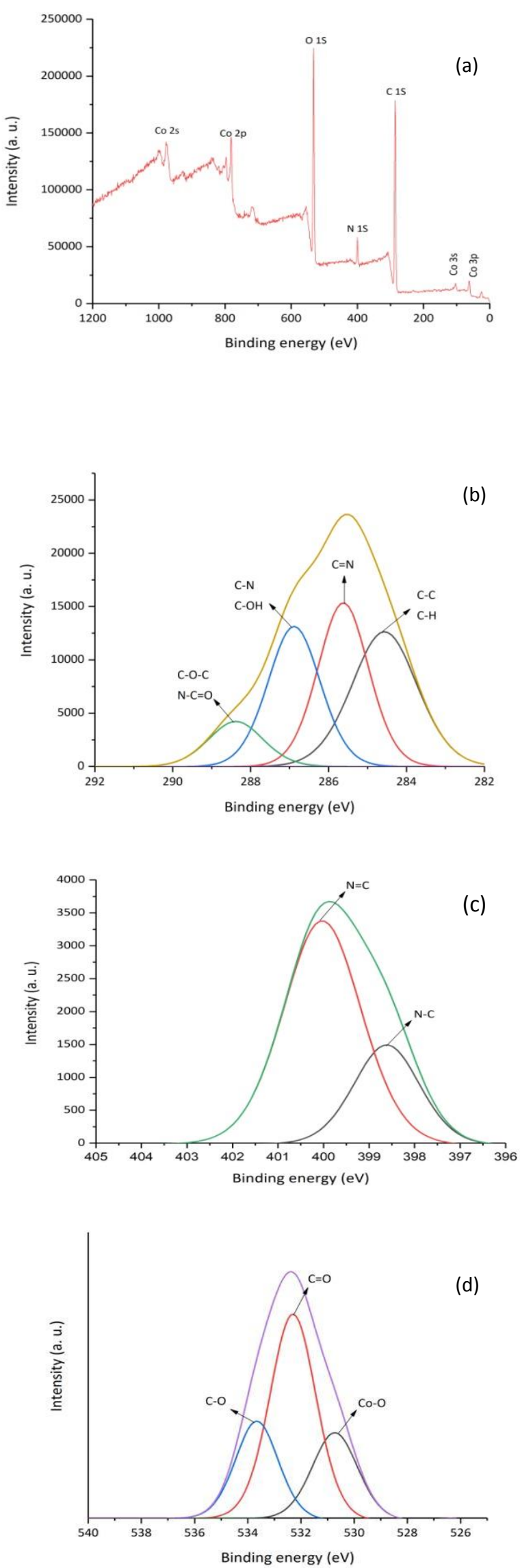


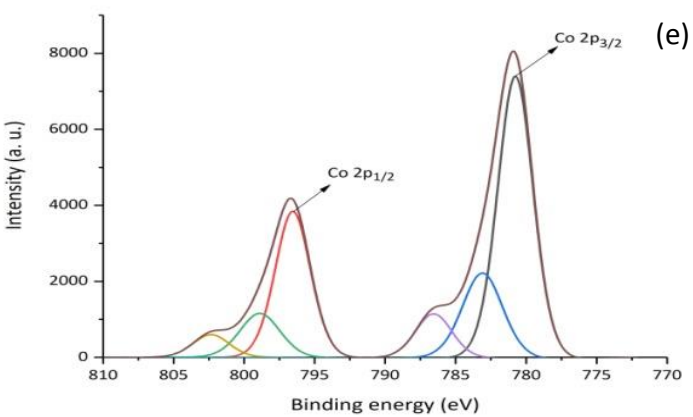

Figure 6. a) XPS patterns of mTEG-CS-Co-Schiff-base, b) C (1s), c) N (1s), d) $\mathrm{O}(1 \mathrm{~s}), \mathrm{e}) \mathrm{CO}$

\section{Catalytic activity of mTEG-CS-Co-Schiff-base in the C-C cross-coupling reactions in water}

Among the $\mathrm{C}-\mathrm{C}$ cross-coupling reactions, Hiyama and Suzuki reactions are efficient tools in organic chemistry for the synthesis of symmetrical and unsymmetrical biphenyl derivatives. ${ }^{19}$ Organosilicon compounds are used in Hiyama cross-coupling reactions. ${ }^{20}$ These compounds are the best alternative to the other reagents such as organozinc or organomagnesium compounds and tin reagents, from an environmental point of view, ease of preparation, stability, low cost and accessibility. ${ }^{21}$ They are also preferred to organoboron compounds which are used in Suzuki reactions. ${ }^{22}$ Since, organoboron compounds are either unstable or difficult to purify and frequently lose boron to give undesirable homocoupling products. Meanwhile, due to the weak polarization of the carbon-silicon bond in organosilicon derivatives, they act as poor cross-coupling partners. Therefore, the nucleophilicity of the organosilicon reagents needs to be enhanced. Fluoride anions are the most commonly activators which employed for this purpose. However, the fluoride ion is a strong base, so base-sensitive protecting groups, acidic protons and functional groups may be affected by the addition of this activator. This limitation has been overcome by replacement of fluoride ions with inorganic bases in water. ${ }^{23}$ The reported procedures in water suffered from one or more of the following drawbacks such as using organic cosolvents, phase transfer catalyst, surfactant or large amount of the catalyst. Following our research on the development of new catalytic systems to perform cross-coupling reactions by environmentally friendly procedures, ${ }^{24}$ herein, we have studied the catalytic activity of mTEG-CS-Co-Schiff-base in fluoride-free Hiyama coupling reactions in water. Based on our literature survey, this is the first report on the application of cobalt catalyst in Hiyama cross-coupling reaction. To probe the catalytic activity of the mTEG-CS-Co-Schiff-base toward the Hiyama cross-coupling reactions, the cross-coupling reaction of iodobenzene with triethoxyphenylsilane in aqueous media was taken as a model reaction. Various reaction parameters such as temperature, base and the amount of the catalyst were screened for the reaction model, and the results are summarized in Table 1. As indicated in
Table 1, of the bases, $\mathrm{NaOH}$ was found to be the most effective (entry 4) presumably due to its better solubility than the other bases in water. In an effort to optimize the amount of the catalyst, the best yield of the product was obtained in the presence of 0.5 mol\% of the catalyst (entry 5). The reaction proceeded with lower yields at lower temperatures (entries 7 and 8). To show the role of the hydrophilic group on the catalyst, the reaction was performed in the presence of CS-Co-Schiff-base. The product was obtained after a longer reaction time (entry 9) compared with mTEG-CS-CoSchiff-base (entry 5). The model reaction was also studied in the presence of $\mathrm{Co}(\mathrm{OAc})_{2}$. It was found that the desired product was obtained in low yield after $24 \mathrm{~h}$ (entry 10$)$.

Table 1. Optimization of Hiyama cross-coupling reaction of iodobenzene with triethoxyphenylsilane.

\begin{tabular}{cccccc}
\hline Entry & $\begin{array}{c}\text { Catalyst } \\
\text { (mol\%) }\end{array}$ & Base & $\begin{array}{c}\mathbf{T} \\
\left({ }^{\circ} \mathbf{C}\right)\end{array}$ & $\begin{array}{c}\text { Time } \\
(\mathbf{h})\end{array}$ & $\begin{array}{c}\text { Isolated Yield } \\
\text { (\%) }\end{array}$ \\
\hline 1 & 1 & $\mathrm{Et}_{3} \mathrm{~N}$ & 90 & $45 \mathrm{~min}$ & 61 \\
2 & 1 & $\mathrm{KF}$ & 90 & 1.5 & 39 \\
3 & 1 & $\mathrm{NaF}$ & 90 & 2.5 & 60 \\
4 & 1 & $\mathrm{NaOH}$ & 90 & 0.5 & 98 \\
5 & 0.5 & $\mathrm{NaOH}$ & 90 & 1 & 98 \\
6 & 0.35 & $\mathrm{NaOH}$ & 90 & 1 & 80 \\
7 & 0.5 & $\mathrm{NaOH}$ & 50 & 1.5 & 72 \\
8 & 0.5 & $\mathrm{NaOH}$ & r.t. & 1 & 61 \\
$9^{\mathrm{b}}$ & 0.5 & $\mathrm{NaOH}$ & 90 & $8(24)$ & $88(88)$ \\
$10^{c}$ & 0.5 & $\mathrm{NaOH}$ & 90 & 24 & 30 \\
\hline
\end{tabular}

aeaction conditions: iodobenzene $(1 \mathrm{mmol})$, triethoxyphenylsilane (1.5 mmol), base $(2 \mathrm{mmol}), \mathrm{H}_{2} \mathrm{O}(3 \mathrm{~mL})$.

${ }^{\mathrm{b}}$ Catalyst without hydrophilic group

${ }^{\mathrm{C}} \mathrm{Co}(\mathrm{OAc})_{2}$

Under the optimized reaction conditions $(0.5 \mathrm{~mol} \%$ of the catalyst, $\mathrm{NaOH}$ and $90^{\circ} \mathrm{C}$ ), the substrate scope of the reaction was examined and the results are shown in Table 2. As it is depicted in Table 2, reactions of both electron-deficient and electron-rich aryl halides (iodides, bromides and chlorides) gave the corresponding biaryl derivatives in good to excellent yields, irrespective of the electronic nature of the substituent.

Table 2. Hyiama reaction of aryl halides with triethoxyphenylsilane catalyzed by $\mathrm{mTEG}$-CS-Co-Schiff-base in water.

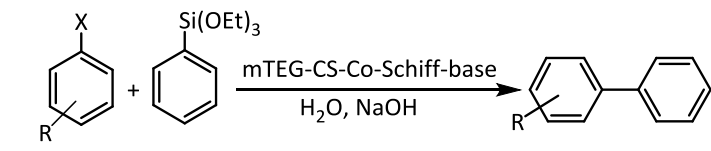

\begin{tabular}{ccccc}
\hline Entry & $\mathbf{X}$ & $\mathbf{R}$ & Time (h) & $\begin{array}{c}\text { Isolated } \\
\text { Yielda (\%) }\end{array}$ \\
\hline 1 & I & H & 1 & 98 \\
2 & I & OMe & 3.5 & 90 \\
\hline
\end{tabular}




\begin{tabular}{ccccc}
\hline 3 & $\mathrm{I}$ & $\mathrm{Cl}$ & 2 & 90 \\
4 & $\mathrm{I}$ & $\mathrm{I}$ & 6 & 93 \\
5 & $\mathrm{Br}$ & $\mathrm{H}$ & 3 & 90 \\
6 & $\mathrm{Br}$ & $\mathrm{Me}$ & 4 & 86 \\
7 & $\mathrm{Br}$ & $\mathrm{OMe}$ & 5 & 80 \\
8 & $\mathrm{Br}$ & $\mathrm{NO}_{2}$ & 2.5 & 95 \\
9 & $\mathrm{Br}$ & $\mathrm{CN}$ & 2.5 & 90 \\
10 & $\mathrm{Br}$ & $\mathrm{Cl}$ & 3 & 87 \\
11 & $\mathrm{Cl}$ & $\mathrm{H}$ & 4 & 90 \\
12 & $\mathrm{Cl}$ & $\mathrm{Me}$ & 5 & 76 \\
13 & $\mathrm{Cl}$ & $\mathrm{NO}_{2}$ & 3 & 90 \\
14 & $\mathrm{Cl}$ & $\mathrm{CN}^{2}$ & 3.5 & 80 \\
\hline
\end{tabular}

aReaction conditions: catalyst (0.5 mol\%), triethoxyphenylsilane (1.5 equiv.), $\mathrm{NaOH}$ (2 equiv.).

To examine the reusability of the catalyst, a recycling experiment was performed with iodobenzene and triethoxyphenylsilane under the optimized reaction conditions. Due to the presence of hydrophilic TEG tag in the catalyst, mTEG-CS-Co-Schiff-base dispersed in the aqueous phase without any affinity to the organic phase (Figure 6). Considering this property, after the first use of the catalyst, the product was simply extracted by EtOAc, while the catalyst remained in the aqueous phase (Figure 6b). Without any isolation of the catalyst, the aqueous phase was recharged with iodobenzene, triethoxyphenylsilane and $\mathrm{NaOH}$ for the next run. After six runs, the catalyst was simply isolated from the aqueous layer by filtration. By this method, no significant loss of the catalytic activity and loss of the catalyst (3\%) were observed after six runs (Figure 7). FT-IR, FE-SEM and XRD of the catalyst after six times reuse showed that the structure and morphology of the catalyst maintained unchanged during the recycling process (Figure 8). Hot filtration test was performed to check if the active catalyst is indeed heterogeneous. After completion of $65 \%$ of the coupling reaction, the solid was separated at the reaction temperature and the liquid phase was allowed to react for $24 \mathrm{~h}$. No further conversion showed that the observed catalysis was heterogeneous in nature. The heterogeneous nature of the catalyst was also examined by a poisoning test using $\mathrm{S}_{8}(0.05 \mathrm{~g})$ as a metal scavenger in the model reaction. Any considerable change in the progress of the reaction was not observed (Figure 9c).

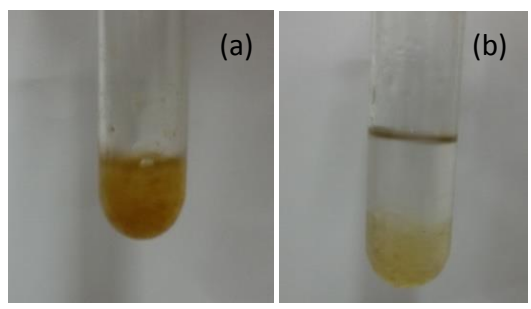

Figure 6. a) Dispersion of mTEG-CS-Co-Schiff-base in water, b) distribution of mTEG-CS-Co-Schiff-base in a biphasic water/EtOAc.

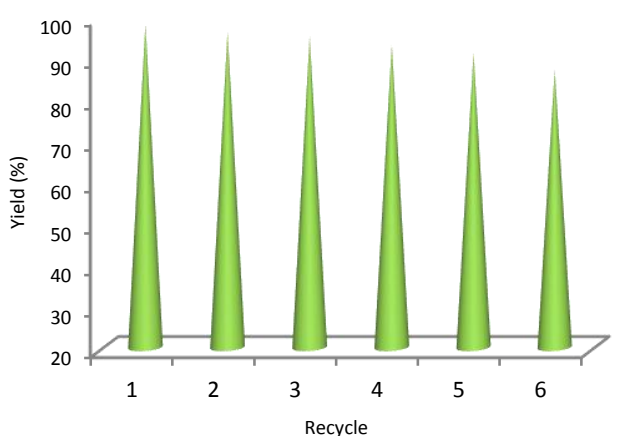

Figure 7. Reusability of mTEG-CS-Co-Schiff-base in the reaction of iodobenzene and triethoxyphenylsilane in aqueous media in $1 \mathrm{~h}$.
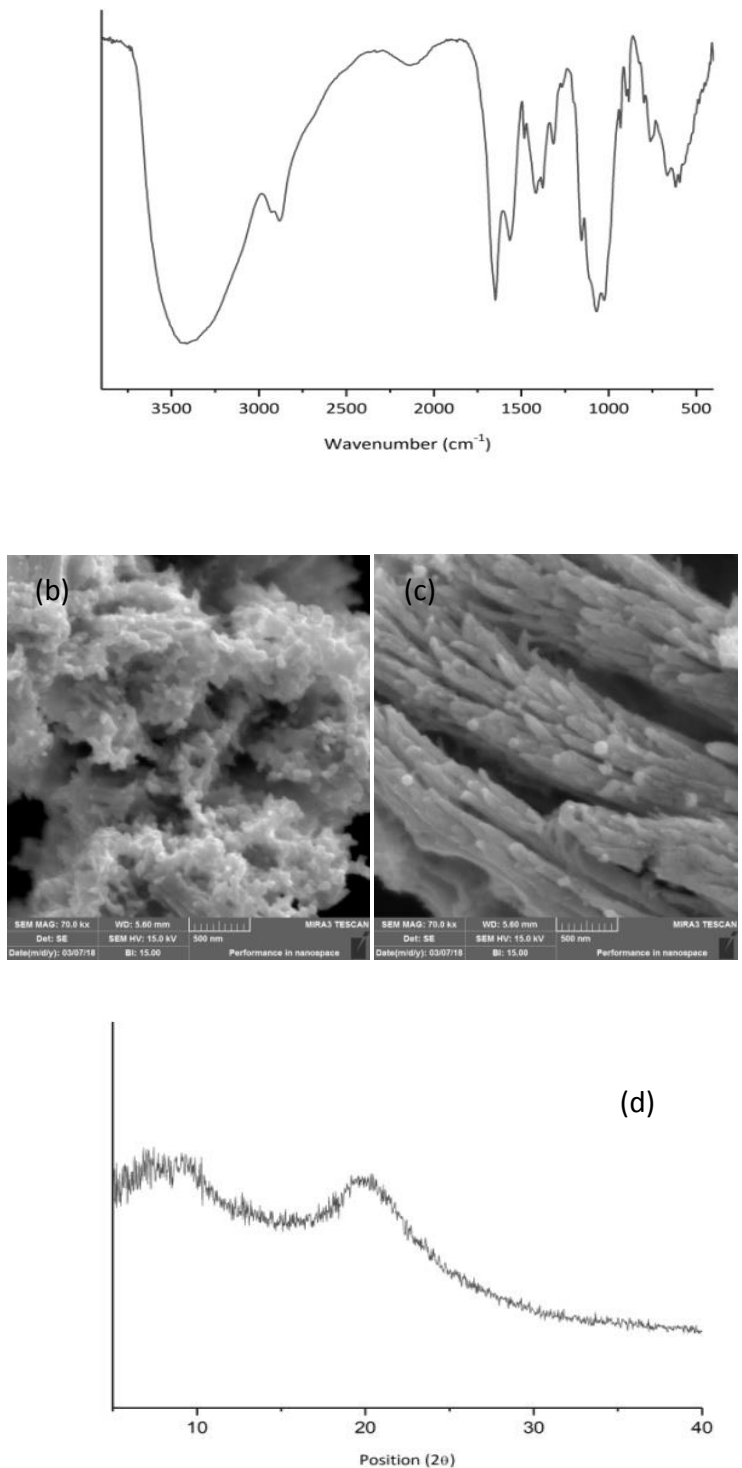

Figure8. a) FT-IR, b,c) FE-SEM images and d) XRD analysis of the mTEG-CS-Co-Schiff-base after six times reuse. 


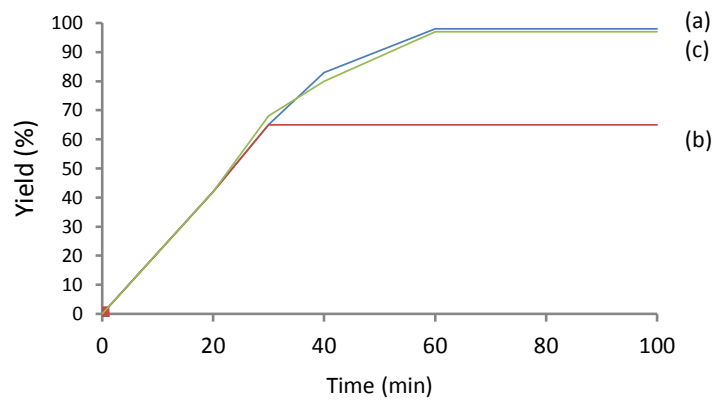

Figure 9. Hiyama coupling reaction of iodobenzene with triethoxyphenylsilane catalyzed by mTEG-CS-Co-Schiff-base in water in a) normal reaction, b) hot filtration test and c) poisoning test.

To test the potential synthetic applications of this method, the reaction of iodobenzene $(50 \mathrm{mmol})$ and triethoxyphenylsilane $(75$ $\mathrm{mmol}$ ) on a larger scale was examined under the optimized reaction conditions. The desired product was obtained in $97 \%$ yield after $3 \mathrm{~h}$. Encouraged by the results of Hiyama reaction, the coupling reaction leading to biaryl compounds was investigated via the Suzuki crosscoupling reaction. At first, the reaction conditions were optimized for the reaction of iodobenzene with phenylbronic acid in aqueous media. The results are summarized in Table 3. As shown in Table 3, among the bases examined (entries 1-5), $\mathrm{K}_{2} \mathrm{CO}_{3}$ was proved to be the best choice (entry 2 ). The model reaction was performed at different temperatures (entries 2, 6-8) and the best result was obtained at $90{ }^{\circ} \mathrm{C}$ (entry 2). The effect of the amount of the catalyst (entries 2, 9-12) was also investigated and found that the reaction proceeded well in the presence of $0.5 \mathrm{~mol} \%$ of the catalyst (entry 9).

Table 3. Suzuki coupling reaction of iodobenzene with phenylbronic acid catalyzed by mTEG-CS-Co-Schiff-base in water under different conditions

\begin{tabular}{cccccc}
\hline Entry & $\begin{array}{c}\text { Catalyst } \\
(\mathbf{m o l} \%)\end{array}$ & Base & $\begin{array}{c}\mathbf{T} \\
\left({ }^{\circ} \mathbf{C}\right)\end{array}$ & $\begin{array}{c}\text { Time } \\
(\mathbf{m i n})\end{array}$ & $\begin{array}{c}\text { Isolated } \\
\text { Yield }{ }^{\mathbf{~}} \text { (\%) }\end{array}$ \\
\hline 1 & 1 & $\mathrm{Et}_{3} \mathrm{~N}$ & 90 & 30 & 58 \\
2 & 1 & $\mathrm{~K}_{2} \mathrm{CO}_{3}$ & 90 & 45 & 93 \\
3 & 1 & $\mathrm{Cs}_{2} \mathrm{CO}_{3}$ & 90 & 30 & 81 \\
4 & 1 & $\mathrm{KOH}$ & 90 & 45 & 52 \\
5 & 1 & $\mathrm{NaOH}$ & 90 & 55 & 29 \\
6 & 1 & $\mathrm{~K}_{2} \mathrm{CO}_{3}$ & r.t & 30 & 60 \\
7 & 1 & $\mathrm{~K}_{2} \mathrm{CO}_{3}$ & 50 & 30 & 71 \\
8 & 1 & $\mathrm{~K}_{2} \mathrm{CO}_{3}$ & 70 & 35 & 82 \\
9 & 0.5 & $\mathrm{~K}_{2} \mathrm{CO}_{3}$ & 90 & 60 & 93 \\
10 & 0.75 & $\mathrm{~K}_{2} \mathrm{CO}_{3}$ & 90 & 50 & 90 \\
11 & 0.25 & $\mathrm{~K}_{2} \mathrm{CO}_{3}$ & 90 & 50 & 61 \\
12 & 0.35 & $\mathrm{~K}_{2} \mathrm{CO}_{3}$ & 90 & 55 & 79 \\
\hline
\end{tabular}

aReaction conditions: iodobenzene ( $1 \mathrm{mmol}$ ), phenylbronic acid (1.1 mmol), base (2 mmol), $\mathrm{H}_{2} \mathrm{O}(3 \mathrm{~mL})$.

With the optimized reaction conditions in hand, we then studied the general usefulness of our new catalytic system in the Suzuki reaction of some aryl halides with phenylbronic acid (Table 4). Under the optimized reaction conditions, different aryl halides (iodides, bromides and chlorides) were successfully converted to the corresponding biaryl products.

Table 4. Suzuki coupling reaction of various aryl halides with phenylbronic acid catalyzed by mTEG-CS-Co-Schiff-base in water.

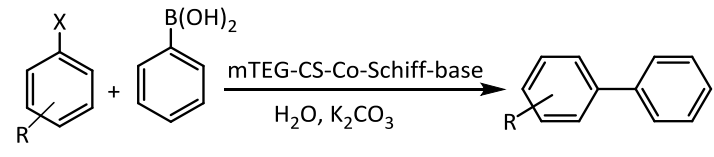

\begin{tabular}{ccccc}
\hline Entry & $\mathbf{x}$ & $\mathbf{R}$ & $\begin{array}{c}\text { Time } \\
\text { (h) }\end{array}$ & $\begin{array}{c}\text { Isolated Yielda } \\
\text { (\%) }\end{array}$ \\
\hline 1 & $\mathrm{I}$ & $\mathrm{H}$ & 1 & 93 \\
2 & $\mathrm{I}$ & $\mathrm{OMe}$ & 3 & 85 \\
3 & $\mathrm{I}$ & $\mathrm{Cl}$ & 1.5 & 90 \\
4 & $\mathrm{I}$ & $\mathrm{I}$ & 5 & 91 \\
5 & $\mathrm{Br}$ & $\mathrm{H}$ & 2 & 90 \\
6 & $\mathrm{Br}$ & $\mathrm{Me}$ & 3.5 & 88 \\
7 & $\mathrm{Br}$ & $\mathrm{OMe}$ & 4 & 82 \\
8 & $\mathrm{Br}$ & $\mathrm{NO} 2$ & 1.5 & 90 \\
9 & $\mathrm{Br}$ & $\mathrm{CN}_{2}$ & 2 & 91 \\
10 & $\mathrm{Br}$ & $\mathrm{Cl}$ & 2.5 & 86 \\
11 & $\mathrm{Cl}$ & $\mathrm{H}$ & 3 & 90 \\
12 & $\mathrm{Cl}$ & $\mathrm{Me}$ & 4 & 78 \\
13 & $\mathrm{Cl}$ & $\mathrm{NO}_{2}$ & 2.5 & 89 \\
14 & $\mathrm{Cl}$ & $\mathrm{CN}^{2}$ & 2.5 & 82 \\
\hline
\end{tabular}

a Reaction conditions: catalyst ( $0.5 \mathrm{~mol} \%)$, aryl halide $(1 \mathrm{mmol})$, phenylbronic acid $(1.1 \mathrm{mmol}), \mathrm{K}_{2} \mathrm{CO}_{3}(2 \mathrm{mmol}), \mathrm{H}_{2} \mathrm{O}(3 \mathrm{~mL}), 90$ ${ }^{\circ} \mathrm{C}$.

Metal catalyzed carbon-carbon bond forming reactions between aryl halides and olefins in the presence of a base (Heck reaction) is a powerful method for the synthesis of various organic molecules. ${ }^{25}$ This reaction is fundamentally catalyzed by palladium catalysts. Recently, some cobalt based catalysts have been reported for the Heck reaction. ${ }^{7 a-f}$ The reported synthetic routes have certain limitations such as requiring high temperature and/or large amount of the catalyst and most importantly use of organic solvents. Moreover, most of the reported methods suffer from lack of generality for the coupling reactions of arylchlorides. In the last part of our studies on the $\mathrm{C}-\mathrm{C}$ coupling reactions, we decided to expand the catalytic application of mTEG-CS-Co-Schiff-base in the Heck reaction. For this reason, various factors including base, temperature and catalyst loading were screened to optimize the Heck reaction conditions of iodobenzene and $n$-butyl acrylate in aqueous media (Table 5). Amongst the bases tested (entries 1-5), highest catalytic activity was observed in the presence of $\mathrm{Et}_{3} \mathrm{~N}$ (entry 1). The effect of various amounts of the catalyst and temperature on the model reaction was also investigated in depth (entries 6-11). The results of these experiments revealed that 0.35 mol\% of the catalyst and $90{ }^{\circ} \mathrm{C}$ are the best optimal reaction conditions (entry 10).

Table 5. Heck cross-coupling reaction of iodobenzene with $n$-butyl acrylate catalyzed by mTEG-CS-Co-Schiff-base in water under different reaction conditions 


\begin{tabular}{cccccc}
\hline Entry & $\begin{array}{c}\text { Catalyst } \\
\text { (mol \%) }\end{array}$ & Base & $\begin{array}{c}\mathbf{T} \\
\left({ }^{\circ} \mathbf{C}\right)\end{array}$ & $\begin{array}{c}\text { Time } \\
(\mathbf{m i n})\end{array}$ & $\begin{array}{c}\text { Isolated Yielda } \\
(\%)\end{array}$ \\
\hline 1 & 0.5 & $\mathrm{Et}_{3} \mathrm{~N}$ & 90 & 20 & 90 \\
2 & 0.5 & $\mathrm{~K}_{2} \mathrm{CO}_{3}$ & 90 & 30 & 91 \\
3 & 0.5 & $\mathrm{KOH}$ & 90 & 60 & 83 \\
4 & 0.5 & $\mathrm{CH}_{3} \mathrm{COOK}^{2}$ & 90 & 30 & 58 \\
5 & 0.5 & $\mathrm{Cs}_{2} \mathrm{CO}_{3}$ & 90 & 40 & 75 \\
6 & 0.5 & $\mathrm{Et}_{3} \mathrm{~N}$ & 70 & 45 & 80 \\
7 & 0.5 & $\mathrm{Et}_{3} \mathrm{~N}$ & 50 & 30 & 60 \\
8 & 0.5 & $\mathrm{Et}_{3} \mathrm{~N}$ & r.t. & 45 & 45 \\
9 & 0.25 & $\mathrm{Et}_{3} \mathrm{~N}$ & 90 & 30 & 84 \\
10 & 0.35 & $\mathrm{Et}_{3} \mathrm{~N}$ & 90 & 30 & 98 \\
11 & - & $\mathrm{Et}_{3} \mathrm{~N}$ & 90 & $24 \mathrm{~h}$ & 10 \\
\hline
\end{tabular}

a Reaction conditions: iodobenzene $(1 \mathrm{mmol})$, olefin $(1.1 \mathrm{mmol})$, base ( $2 \mathrm{mmol}), \mathrm{H}_{2} \mathrm{O}(3 \mathrm{~mL})$.

Then the scope and limitation of this catalytic system for different substrates were explored and the results were summarized in Table 6. As shown in Table 6, different aryl iodides were coupled with different alkenes such as $n$-butyl/methyl/ethyl acrylate and methyl methacrylate in the presence of the catalyst under optimized reaction conditions and the desired products were obtained in 65$98 \%$ yields (entries 1-6). The coupling reaction of aryl bromides and chlorides (far cheaper and more widely available than aryl iodides and bromides) with $n$-butyl acrylate proceeded well and the corresponding products produced in good to high yields (entries 712). The applicability of this method for the coupling reaction of aryl halides with styrene was also investigated. The examined aryl halides underwent the coupling reactions and gave the desired products in relatively good yields (entries 13-19).

Table 6. Heck cross-coupling reaction of different arylhalides with olefins catalyzed by mTEG-CS-Co-Schiff-base in water.

\begin{tabular}{|c|c|c|c|c|}
\hline Entry & Aryl halide & Olefin & $\begin{array}{l}\text { Time } \\
\text { (h) }\end{array}$ & $\begin{array}{l}\text { Isolateda }^{\text {I }} \\
\text { yield (\%) }\end{array}$ \\
\hline 1 & Phl & $\mathrm{CH}_{2}=\mathrm{CH}-\mathrm{CO}_{2} \mathrm{Bu}^{n}$ & 0.5 & 98 \\
\hline 2 & $\mathrm{Phl}$ & $\mathrm{CH}_{2}=\mathrm{CH}-\mathrm{CO}_{2} \mathrm{Me}$ & 0.5 & 92 \\
\hline 3 & Phl & $\mathrm{CH}_{2}=\mathrm{CH}-\mathrm{CO}_{2} \mathrm{Et}$ & 0.5 & 95 \\
\hline 4 & $\mathrm{Phl}$ & $\begin{array}{c}\mathrm{CH}_{2}=\mathrm{C}(\mathrm{Me})- \\
\mathrm{CO}_{2} \mathrm{Me}\end{array}$ & $\begin{array}{c}45 \\
\min \end{array}$ & 92 \\
\hline 5 & 4- $\mathrm{MeOC}_{6} \mathrm{H}_{4} \mathrm{I}$ & $\mathrm{CH}_{2}=\mathrm{CH}-\mathrm{CO}_{2} \mathrm{Bu}^{n}$ & 4 & 65 \\
\hline 6 & 4- $\mathrm{ClC}_{6} \mathrm{H}_{4} \mathrm{I}$ & $\mathrm{CH}_{2}=\mathrm{CH}-\mathrm{CO}_{2} \mathrm{Bu}^{n}$ & 1.5 & 83 \\
\hline 7 & $\mathrm{PhBr}$ & $\mathrm{CH}_{2}=\mathrm{CH}-\mathrm{CO}_{2} \mathrm{Bu}^{n}$ & 1 & 90 \\
\hline
\end{tabular}

$\begin{array}{ccccc}8 & 4-\mathrm{O}_{2} \mathrm{NC}_{6} \mathrm{H}_{4} \mathrm{Br} & \mathrm{CH}_{2}=\mathrm{CH}-\mathrm{CO}_{2} \mathrm{Bu}^{n} & 1 & 80 \\ 9 & 4-\mathrm{NCC}_{6} \mathrm{H}_{4} \mathrm{Br} & \mathrm{CH}_{2}=\mathrm{CH}-\mathrm{CO}_{2} \mathrm{Bu}^{n} & 1 & 85 \\ 10 & \mathrm{PhCl} & \mathrm{CH}_{2}=\mathrm{CH}-\mathrm{CO}_{2} \mathrm{Bu}^{n} & 2.5 & 82 \\ 11 & 4-\mathrm{O}_{2} \mathrm{NC}_{6} \mathrm{H}_{4} \mathrm{Cl} & \mathrm{CH}_{2}=\mathrm{CH}-\mathrm{CO}_{2} \mathrm{Bu}^{n} & 2 & 80 \\ 12 & 4-\mathrm{NCC}_{6} \mathrm{H}_{4} \mathrm{Cl} & \mathrm{CH}_{2}=\mathrm{CH}-\mathrm{CO}_{2} \mathrm{Bu}^{n} & 2 & 92 \\ 13 & \mathrm{Phl} & \mathrm{Ph} \mathrm{CH}=\mathrm{CH}_{2} & 1.5 & 90 \\ 14 & 4-\mathrm{MeOC}_{6} \mathrm{H}_{4} \mathrm{ll} & \mathrm{Ph} \mathrm{CH}=\mathrm{CH}_{2} & 3 & 73 \\ 15 & 4-\mathrm{ClC}_{6} \mathrm{H}_{4} \mathrm{l} & \mathrm{Ph} \mathrm{CH}=\mathrm{CH}_{2} & 2 & 94 \\ 16 & \mathrm{PhBr}_{16} & \mathrm{Ph} \mathrm{CH}=\mathrm{CH}_{2} & 2 & 85 \\ 17 & 4-\mathrm{NCC}_{6} \mathrm{H}_{4} \mathrm{Br} & \mathrm{Ph} \mathrm{CH}=\mathrm{CH}_{2} & 1.5 & 72 \\ 18 & 4-\mathrm{O}_{2} \mathrm{NC}_{6} \mathrm{H}_{4} \mathrm{Br} & \mathrm{Ph} \mathrm{CH}=\mathrm{CH}_{2} & 1.5 & 80 \\ 19 & \mathrm{PhCl}_{19} & \mathrm{Ph} \mathrm{CH}=\mathrm{CH}_{2} & 4 & 82\end{array}$

aeaction conditions: catalyst $(0.35 \mathrm{~mol} \%)$, aryl halide $(1 \mathrm{mmol})$, olefine $(1.1 \mathrm{mmol}), \mathrm{Et}_{3} \mathrm{~N}(2 \mathrm{mmol}), \mathrm{H}_{2} \mathrm{O}(3 \mathrm{~mL}), 90{ }^{\circ} \mathrm{C}$. Trans isomer of the products were obtained based on ${ }^{3} \mathrm{~J}_{\mathrm{H}-\mathrm{H}}$ value of $16.0-16.4 \mathrm{~Hz}$ for vinyllic hydrogens in ${ }^{1} \mathrm{H} N M R$.

\section{Catalytic activity of mTEG-CS-Co-Schiff-base in $\mathrm{C}\left(\mathbf{s p}^{2}\right)-\mathrm{P}$ cross-coupling reactions in water}

Arylphosphonates are valuable intermediates in organic synthesis ${ }^{26}$ and versatile ligands in catalytic reactions. ${ }^{27}$ They found numerous practical applications in medicinal and polymer chemistry, ${ }^{28}$ designing fuel cell membranes ${ }^{29}$ and building blocks in construction of metal-organic frameworks (MOFs). ${ }^{30}$ They were used in designing new materials with special optical properties, ${ }^{31}$ which have been employed in solar cells. ${ }^{32}$ In the 1980 s, Hirao and coworkers described the first examples of coupling of aryl and vinyl halide with dialkylphosphites using a Pd catalyst. ${ }^{33}$ This method has been later successfully extended to other coupling partners such as aryl triflates, tosylates, diazonium salts, triaryl bismuth, aryl hydrazine and arylbronic acid. ${ }^{34}$ The transition metals used so far for $\mathrm{C}\left(\mathrm{sp}^{2}\right)-\mathrm{P}$ bond formation by cross-coupling reaction are palladium, ${ }^{35}$ copper, ${ }^{36}$ manganese, ${ }^{37}$ nickel, ${ }^{38}$ gold $^{39}$ and silver. ${ }^{40}$ Surprisingly, there is only one report on the use of cobalt for $C\left(\mathrm{sp}^{2}\right)-\mathrm{P}$ bond formation, ${ }^{71}$ although cobalt is a low cost, easily available and relatively environmentally benign metal. However, this reported method suffers from severe problems related to the separation and recovery of the homogeneous catalyst, use of toxic organic solvent, high temperature, and requiring copper iodide and argon atmosphere. ${ }^{71}$ To address these limitations, we have studied the cross-coupling reaction of aryl halides with triethylphosphite catalyzed by mTEG-CS-Co-Schiff-base in water. For this purpose, the coupling reaction of iodobenzene $(1 \mathrm{mmol})$ with triethylphosphite $(2 \mathrm{mmol})$ in the presence of mTEG-CS-Co-Schiff-base in water $(4 \mathrm{~mL})$ was chosen as a model reaction to find the best suitable reaction 
conditions. The effect of some parameters such as base, temperature and amount of the catalyst on the reaction yield and time was investigated (Table 7). The best results were obtained in the presence of $\mathrm{Et}_{3} \mathrm{~N}$ as the base and $2 \mathrm{~mol} \%$ of the catalyst at $80^{\circ} \mathrm{C}$ (Table 7, entry 1).

Table 7. The effect of different parameters on the cross-coupling reaction of iodobenzene and triethylphosphite catalyzed by mTEGCS-Co-Schiff-base

\begin{tabular}{cccccc}
\hline Entry & $\begin{array}{c}\text { Catalyst } \\
\text { (mol\%) }\end{array}$ & Base & $\mathbf{T}\left({ }^{\circ} \mathrm{C}\right)$ & $\begin{array}{c}\text { Time } \\
\text { (h) }\end{array}$ & $\begin{array}{c}\text { Isolated } \\
\text { Yield } \\
(\%)\end{array}$ \\
\hline 1 & 2 & $\mathrm{Et}_{3} \mathrm{~N}$ & 80 & 5 & 92 \\
2 & 2 & $\mathrm{~K}_{2} \mathrm{CO}_{3}$ & 80 & 4 & 63 \\
3 & 2 & $\mathrm{Cs}_{2} \mathrm{CO}_{3}$ & 80 & 3 & 41 \\
4 & 2 & $\mathrm{NaOH}_{2}$ & 80 & 6 & 45 \\
5 & 2 & $\mathrm{Et}_{3} \mathrm{~N}$ & r.t. & 9 & 39 \\
6 & 2 & $\mathrm{Et}_{3} \mathrm{~N}$ & 50 & 3 & 64 \\
7 & 1 & $\mathrm{Et}_{3} \mathrm{~N}$ & 80 & 6 & 72 \\
8 & 0.5 & $\mathrm{Et}_{3} \mathrm{~N}$ & 80 & 8 & 55 \\
9 & - & $\mathrm{Et}_{3} \mathrm{~N}$ & 80 & 24 & - \\
\hline
\end{tabular}

a Reaction conditions: iodobenzene $(1 \mathrm{mmol})$, triethylphosphite (2 $\mathrm{mmol})$, base (3 $\mathrm{mmol}), \mathrm{H}_{2} \mathrm{O}(4 \mathrm{~mL})$.

To examine the scope of this method, the $\mathrm{C}\left(\mathrm{sp}^{2}\right)-\mathrm{P}$ cross-coupling reaction of various halobenzenes with triethylphosphite was studied under optimal reaction conditions (Table 8). As indicated in Table 8, the reaction of triethylphosphite with different aryl iodides, bromides and chlorides containing electron-withdrawing or electron-releasing groups proceeded well and the desired products were isolated in 75-92\% yields. Both halogens in 1,4-diiodo and 1,4dibromobenzene were replaced by twice amount of triethylphosphite under the present reaction conditions (Table 8 , entries 13 and 14).

Table 8. $C\left(\mathrm{sp}^{2}\right)-\mathrm{P}$ cross-coupling reaction of different halobenzenes and triethylphosphite catalyzed by mTEG-CS-Co-Schiff-base

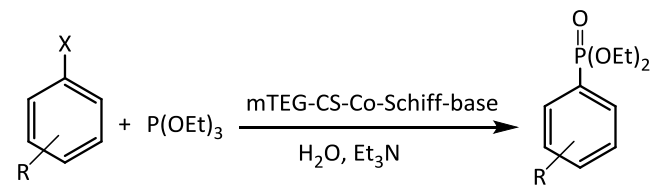

\begin{tabular}{cccc}
\hline Entry & Aryl halide & Time (h) & $\begin{array}{c}\text { Isolated }^{\text {a }} \\
\text { Yield (\%) }\end{array}$ \\
\hline 1 & $\mathrm{C}_{6} \mathrm{H}_{5} \mathrm{I}$ & 5 & 92 \\
2 & $4-\mathrm{ClC}_{6} \mathrm{H}_{4} \mathrm{I}$ & 4.5 & 91 \\
3 & $4-\mathrm{C}_{6} \mathrm{H}_{4} \mathrm{I}$ & 6 & 90 \\
4 & $\mathrm{C}_{6} \mathrm{H}_{5} \mathrm{Br}$ & 6 & 84 \\
5 & $4-\mathrm{MeOC}_{6} \mathrm{H}_{4} \mathrm{Br}$ & 7 & 79 \\
6 & $4-\mathrm{NO}_{2} \mathrm{C}_{6} \mathrm{H}_{4} \mathrm{Br}$ & 5 & 86 \\
7 & $4-\mathrm{MeC}_{6} \mathrm{H}_{4} \mathrm{Br}$ & 6 & 87 \\
8 & $4-\mathrm{BrC}_{6} \mathrm{H}_{4} \mathrm{Br}$ & 5 & 82 \\
9 & $\mathrm{C}_{6} \mathrm{H}_{5} \mathrm{CH}=\mathrm{CHBr}$ & 9.5 & 75 \\
\hline
\end{tabular}

\begin{tabular}{cccc}
\hline 10 & $\mathrm{C}_{6} \mathrm{H}_{5} \mathrm{Cl}$ & 9 & 83 \\
11 & $4-\mathrm{NO}_{2} \mathrm{C}_{6} \mathrm{H}_{4} \mathrm{Cl}$ & 8 & 86 \\
12 & $4-\mathrm{MeC}_{6} \mathrm{H}_{4} \mathrm{Cl}$ & 10 & 78 \\
$13^{\mathrm{b}}$ & $\mathrm{IC}_{6} \mathrm{H}_{4} \mathrm{I}$ & 9 & 89 \\
$14^{\mathrm{b}}$ & $\mathrm{BrC}_{6} \mathrm{H}_{4} \mathrm{Br}$ & 10 & 86 \\
\hline
\end{tabular}

a Reaction conditions: catalyst (1 mol\%), iodobenzene (1 mmol), triethylphosphite (2 mmol), base ( $3 \mathrm{mmol}), \mathrm{H}_{2} \mathrm{O}(4 \mathrm{~mL})$.

${ }^{b}$ triethylphosphite $(4 \mathrm{mmol})$

The recyclability of $\mathrm{mTEG}$-CS-Co-Schiff-base was investigated in a model reaction of iodobenzene in Suzuki, Heck and Hirao cross-coupling reactions with phenylbronic acid, $n$-butyl acrylate, triethylphosphite, respectively, under optimized reaction conditions. EtOAc was added to the reaction mixtures after $1,0.5$ and $5 \mathrm{~h}$, respectively. The products were simply extracted by EtOAc, while the catalyst remained in the aqueous phase. The aqueous phase was recharged with the starting material and reagents. As shown in Figure 10, the catalyst could be reused for six consecutive runs without any significant loss of its activity.

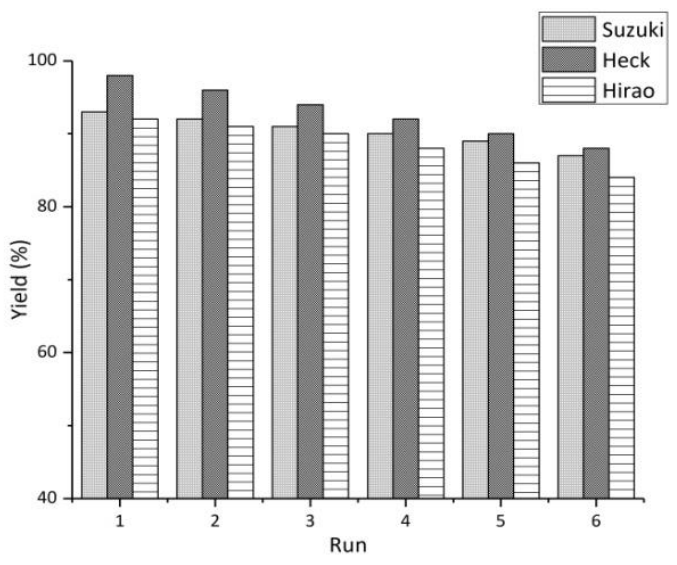

Figure 10. Reusability of mTEG-CS-Co-Schiff-base in Suzuki, Heck and Hirao reactions.

It is worth to note that a few mechanism studies have been conducted with cobalt-catalyzed cross-coupling

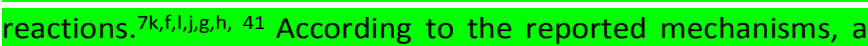
plausible mechanism for the cross-coupling reactions catalyzed by mTEG-CS-Co-Schiff-base is postulated in Scheme 3. As depicted in Scheme 3, at first, the reaction was supposed to be started by in-situ reduction of Co (II) in the catalyst to Co (I) or Co (0) species under basic conditions. ${ }^{7 h}$ Then, upon the oxidative addition of aryl halides to the reduced Co species, aryl cobalt intermediate (I) was formed. In the Hiyama and Suzuki cross-coupling reactions, transmetallation of aryl cobalt intermediate (I) with triethoxyphenylsilane or phenylbronic acid afforded intermediate II, which underwent reductive elimination to produce the biaryl products. In the Heck crosscoupling reaction, a $\pi$-complex was formed by the olefin coordination to the aryl cobalt intermediate (I). A migratory insertion of the olefin followed by $\beta$-hydride elimination afforded the Heck products. To check a possible radical 
mechanism for the Heck reaction, ${ }^{41 a}$ the reaction of iodobenzene with $n$-butyl acrylate under optimized reaction conditions was studied in the presence of an electron trap. For this purpose, hydroquinone was added to the reaction mixture after $15 \mathrm{~min}$. Any change in the progress of the reaction compared with the normal conditions, confirmed that any radical was not formed during the coupling process (Figure 11). In the Hirao cross-coupling reaction, aryl cobalt intermediate (I) reacted with triethylphosphite to afford intermediate III. Arylphosphonates were produced from intermediate III by ethyl halide elimination through an Arbuzov-type reaction followed by reductive elimination. Subsequently, in each cycle, the active cobalt species were regenerated in the presence of the base and returned to the catalytic cycle. Finally, aerobic oxidation furnished the Co (II) catalyst.

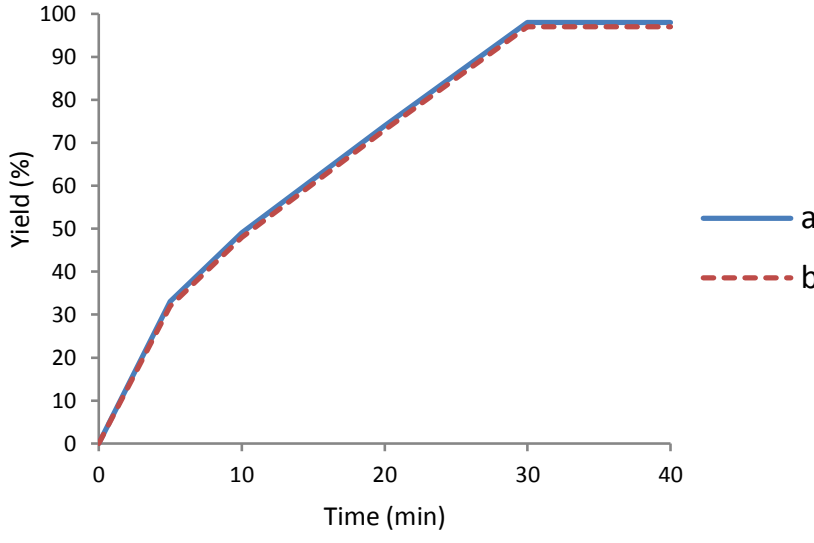

Figure 11. Heck coupling reaction of iodobenzene with $n$-butyl acrylate catalyzed by mTEG-CS-Co-Schiff-base in water in a) normal reaction and b) presence of an electron trap.

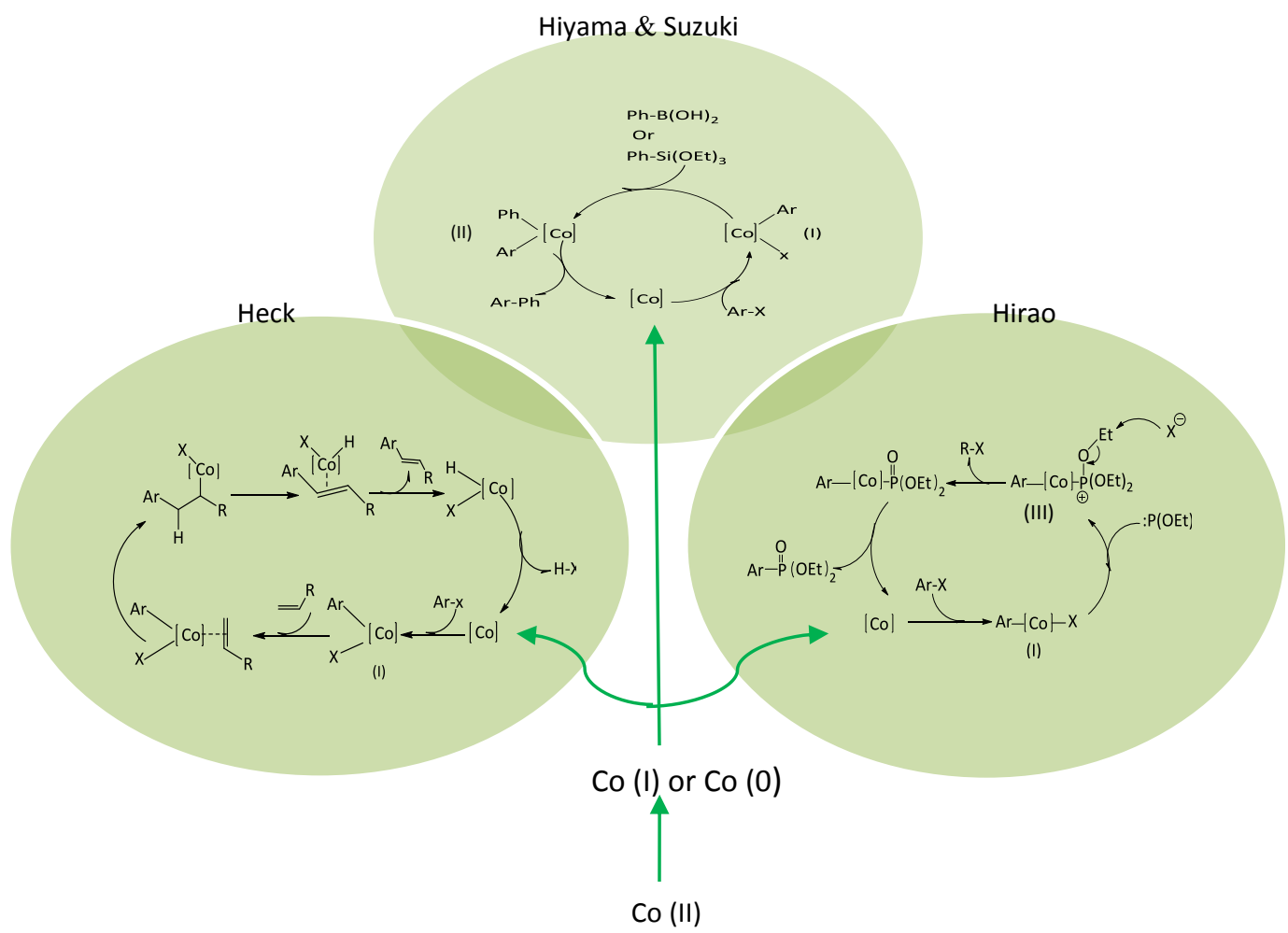

Scheme 3. A plausible mechanism for the Hiyama, Suzuki, Heck and Hirao cross-coupling reactions catalyzed by mTEG-CS-Co-Schiff-base

In the last part of studies, the activity of mTEG-CS-Co-Schiff-base was compared with those of some reported Co catalysts in the Heck, Suzuki and Hirao reactions (Table 9). ${ }^{7}$ As depicted in Table 9, mTEG-CS-Co-Schiff-base is the most effective catalyst for the C-C and $\mathrm{C}\left(\mathrm{sp}^{2}\right)-\mathrm{P}$ coupling reactions of aryliodides, bromides and chlorides (the most challenging arylhalides which are far cheaper and more widely available than aryl iodides and bromides). Notably, most of the reported methods suffer from lack of generality for the coupling reactions of arylchlorides. Moreover, the reported synthetic routes have certain limitations such as requiring high temperature and/or large amount of the catalyst and most importantly use of organic solvents. Promising results obtained in the presence of mTEG-CS-Co-Schiff-base should be attributed to the water dispersibility of the catalyst. The waterdispersibility ensures the better contact between the catalyst and the reactants, thus significantly enhances the catalytic activity and stability of the catalyst. 


\section{ARTICLE}

Table 9. Comparison of catalytic activity of our catalyst with some reported cobalt catalysts for Heck, Suzuki and Hirao cross-coupling reactions

\begin{tabular}{|c|c|c|c|c|c|c|}
\hline Entry ${ }^{\text {ref }}$ & Catalyst (mol\%) & Reaction & Reaction conditions & $\mathbf{x}$ & Time (h) & Yield (\%) \\
\hline $1^{7 a}$ & Co-B amorphous alloy (5) & Heck & $\mathrm{H}_{2} \mathrm{O} / \mathrm{DMF}, 130{ }^{\circ} \mathrm{C}$ & 1 & $12-24$ & $95-100$ \\
\hline \multirow{3}{*}{$2^{7 b}$} & \multirow{3}{*}{ Nano Co (2) } & \multirow{3}{*}{ Heck } & \multirow{3}{*}{$\mathrm{NMP}, 130^{\circ} \mathrm{C}$} & 1 & $12-24$ & $67-85$ \\
\hline & & & & $\mathrm{Br}$ & $20-30$ & $40-73$ \\
\hline & & & & $\mathrm{Cl}$ & 30 & Trace \\
\hline \multirow{2}{*}{$3^{7 c}$} & \multirow{2}{*}{ Co-NHC@MWCNT (0.35) } & \multirow{2}{*}{ Heck } & \multirow{2}{*}{ PEG, $80^{\circ} \mathrm{C}$} & 1 & $5-8$ & $74-92$ \\
\hline & & & & $\mathrm{Br}$ & $6-10$ & $58-80$ \\
\hline \multirow{3}{*}{$4^{7 d}$} & \multirow{3}{*}{ Co-MS@MNPs/CS (1.1) } & \multirow{3}{*}{ Heck } & \multirow{3}{*}{ PEG, $80^{\circ} \mathrm{C}$} & 1 & 1 & $69-92$ \\
\hline & & & & $\mathrm{Br}$ & 1 & $15-87$ \\
\hline & & & & $\mathrm{Cl}$ & 1 & $30-71$ \\
\hline $5^{7 e}$ & $\mathrm{Co} / \mathrm{Al}_{2} \mathrm{O}_{3}(10)$ & Heck & $\mathrm{NMP}, 150{ }^{\circ} \mathrm{C}$ & 1 & 24 & $21-85$ \\
\hline \multirow{3}{*}{$6^{7 f}$} & \multirow{3}{*}{$\mathrm{Fe}_{3} \mathrm{O}_{4} @ B o e h m i t e-\mathrm{NH}_{2}-\mathrm{Co}(0.44)$} & \multirow{3}{*}{ Heck } & \multirow{3}{*}{$\mathrm{H}_{2} \mathrm{O}, 80^{\circ} \mathrm{C}$} & 1 & $0.4-3$ & $25-98$ \\
\hline & & & & $\mathrm{Br}$ & $0.8-5$ & $40-90$ \\
\hline & & & & $\mathrm{Cl}$ & $3-7$ & $15-40$ \\
\hline \multirow{3}{*}{$7^{\text {This work }}$} & \multirow{3}{*}{ mTEG-CS-Co-Schiff-base (0.35) } & \multirow{3}{*}{ Heck } & \multirow{3}{*}{$\mathrm{H}_{2} \mathrm{O}, 90^{\circ} \mathrm{C}$} & 1 & $0.5-3$ & $65-98$ \\
\hline & & & & $\mathrm{Br}$ & $1-2$ & $72-90$ \\
\hline & & & & $\mathrm{Cl}$ & $2-4$ & $80-92$ \\
\hline \multirow{2}{*}{$8^{7 g}$} & \multirow{2}{*}{$\mathrm{Co@GO/Fe} 3 \mathrm{O}_{4} / \mathrm{L}-\mathrm{dopa}^{\mathrm{a}}$ (1.84) } & \multirow{2}{*}{ Suzuki } & \multirow{2}{*}{$\mathrm{H}_{2} \mathrm{O}, 100^{\circ} \mathrm{C}$} & $\mathrm{Br}$ & $4-8$ & $65-82$ \\
\hline & & & & $\mathrm{Cl}$ & $5-7.25$ & $62-72$ \\
\hline \multirow{3}{*}{$9^{7 \mathrm{~h}}$} & \multirow{3}{*}{ Cobalt pincer complex (0.5) } & \multirow{3}{*}{ Suzuki } & \multirow{3}{*}{$\mathrm{CH}_{3} \mathrm{CN}, 80^{\circ} \mathrm{C}$} & 1 & 16 & $71-90$ \\
\hline & & & & $\mathrm{Br}$ & 16 & $40-83$ \\
\hline & & & & $\mathrm{Cl}$ & 16 & 68 \\
\hline & & & & 1 & 16 & $58-79^{c}$ \\
\hline $10^{n}$ & Cobalt Schift-base complex ${ }^{\circ}(2)$ & Suzuki & $\mathrm{CH}_{3} \mathrm{CN}, 80^{\circ} \mathrm{C}$ & $\mathrm{Br}$ & 16 & $40-83^{c}$ \\
\hline & & & & 1 & 8 & $97.1^{\mathrm{C}}$ \\
\hline $11^{7 j}$ & $\operatorname{CoASGO}^{d}(0.32)$ & Suzuki & $\mathrm{EtOH}, 80^{\circ} \mathrm{C}$ & $\mathrm{Br}$ & 12,24 & $45-89$ \\
\hline & & & & $\mathrm{Cl}$ & 24 & 18,23 \\
\hline $12^{7 \mathrm{k}}$ & Cobalt salen complexe (2) & Suzuki & & 1 & 8 & 68,85 \\
\hline $12 *$ & Covall salen comprex $(\angle)$ & & Retluxing 1,4-dioxane & $\mathrm{Br}$ & 8 & $35-80$ \\
\hline & & & & 1 & $0.4-3$ & $60-98$ \\
\hline $13^{7 f}$ & $\mathrm{Fe}_{3} \mathrm{O}_{4} @$ Boehmite- $\mathrm{NH}_{2}$-Co (0.33) & Suzuki & $\mathrm{H}_{2} \mathrm{O}, 80^{\circ} \mathrm{C}$ & $\mathrm{Br}$ & $0.5-4$ & $50-95$ \\
\hline & & & & $\mathrm{Cl}$ & $2-9$ & $15-65$ \\
\hline & & & & 1 & $1-3$ & $85-93$ \\
\hline $14^{\text {This work }}$ & mTEG-CS-Co-Schiff-base (0.5) & Suzuki & $\mathrm{H}_{2} \mathrm{O}, 90^{\circ} \mathrm{C}$ & $\mathrm{Br}$ & $1.5-4$ & $82-91$ \\
\hline & & & & $\mathrm{Cl}$ & $2-3$ & $82-90$ \\
\hline
\end{tabular}




\begin{tabular}{|c|c|c|c|c|c|c|}
\hline $15^{71}$ & $\mathrm{Co}(\mathrm{acac})_{2}(5) / \mathrm{Cul}(5)$ & Hirao & $\mathrm{NMP}, 110^{\circ} \mathrm{C}$ & $\begin{array}{c}\mathrm{I} \\
\mathrm{Br}\end{array}$ & $\begin{array}{l}10 \\
10\end{array}$ & $\begin{array}{l}76-89 \\
73-83\end{array}$ \\
\hline \multirow[t]{3}{*}{$16^{\text {This work }}$} & mTEG-CS-Co-Schiff-base (2) & Hirao & $\mathrm{H}_{2} \mathrm{O}, 80^{\circ} \mathrm{C}$ & 1 & $4.5-5$ & $91-92$ \\
\hline & & & & $\mathrm{Br}$ & $5-9.5$ & $75-86$ \\
\hline & & & & $\mathrm{Cl}$ & $8-10$ & $78-86$ \\
\hline
\end{tabular}

\footnotetext{
a L-3,4-Dihydroxyphenylalanine

${ }^{\mathrm{b}} \mathrm{A}$ complex between 4-aminoacetophenone, salicylaldehyde and cobalt acetate

c GC yield

${ }^{d}$ Cobalt Schiff-base immobilized on graphene nanosheet

e A salen of $o$-phenylenediamine and salicylaldehyde
}

\section{Experimental}

\section{Synthesis of mTEG-CS-Schiff-base}

Tosylated mono-methoxytriethylene glycol${ }^{42}(20 \mathrm{mmol})$ was added to the stirring mixture of CS-Schiff-base ${ }^{43}$ and $\mathrm{K}_{2} \mathrm{CO}_{3}(20 \mathrm{mmol})$ in dry $\mathrm{CH}_{3} \mathrm{CN}(50 \mathrm{~mL})$ and stirred at $60{ }^{\circ} \mathrm{C}$ for $24 \mathrm{~h}$. The reaction was allowed to be cooled to room temperature. The solid material was separated by filtration and washed with EtOH $(3 \times 20 \mathrm{~mL})$ and $\mathrm{H}_{2} \mathrm{O}(3$ $\times 20 \mathrm{~mL}$ ) and dried in vacuum oven at $50{ }^{\circ} \mathrm{C}$ for $24 \mathrm{~h}$ to give mTEGCS-Schiff-base.

\section{Synthesis of mTEG-CS-Co-Schiff-base}

Cobalt acetate $(4 \mathrm{mmol}$ ) was added to the mixture of mTEG-CSSchiff-base $(1 \mathrm{~g})$ in EtOH $(15 \mathrm{~mL})$ and stirred at $80{ }^{\circ} \mathrm{C}$ for $24 \mathrm{~h}$. Then the reaction was allowed to be cooled to room temperature. The mixture was filtered off and washed with $\mathrm{EtOH}(3 \times 20 \mathrm{~mL})$ and dried in an oven at $60^{\circ} \mathrm{C}$ for $24 \mathrm{~h}$.

\section{General procedure for Hiyama cross-coupling reaction}

mTEG-CS-Co-Schiff-base $(0.008 \mathrm{~g}, 0.5 \mathrm{~mol} \%)$ was added to the stirring mixture of aryl halide $(1 \mathrm{mmol}), \mathrm{NaOH}(2 \mathrm{mmol})$, triethoxyphenylsilane $(1.5 \mathrm{mmol})$ in $\mathrm{H}_{2} \mathrm{O}(3 \mathrm{~mL})$. The above mixture was heated at $90{ }^{\circ} \mathrm{C}$ in an oil bath. The reaction progress was monitored by TLC. After passing the time mentioned in Table 2, the reaction mixture was allowed to be cooled to ambient temperature. The organic compound was extracted with EtOAc $(3 \times 5 \mathrm{~mL})$ from aqueous layer while the catalyst was left in the aqueous phase. The separated organic layer was dried by anhydrous $\mathrm{MgSO}_{4}$ and filtered. The organic solvent was evaporated in vacuum to produce the crude product. The pure products were isolated by chromatography on silica gel $(n$-hexane:EtOAc $=50: 1)$. The aqueous phase which contains the catalyst was used for another run.

\section{General procedure for Suzuki cross-coupling reaction}

mTEG-CS-Co-Schiff-base (0.008 g, $0.5 \mathrm{~mol} \%)$ was added to the stirring mixture of aryl halide (1 $\mathrm{mmol}), \mathrm{K}_{2} \mathrm{CO}_{3}(2 \mathrm{mmol})$, phenylbronic acid $(1.1 \mathrm{mmol})$ in $\mathrm{H}_{2} \mathrm{O}(3 \mathrm{~mL})$. The above mixture was heated at $90{ }^{\circ} \mathrm{C}$ in an oil bath. The reaction progress was monitored by TLC. After passing the time mentioned in Table 4 , the reaction mixture was allowed to be cooled to ambient temperature. The organic compound was extracted with EtOAc $(3 \times 5 \mathrm{~mL})$ from aqueous layer while the catalyst was left in the aqueous phase. The separated organic layer was dried by anhydrous $\mathrm{MgSO}_{4}$ and filtered. The organic solvent was evaporated in vacuum to produce the crude product. The pure products were isolated by chromatography on silica gel $(n$-hexane:EtOAc $=50: 1)$. The aqueous phase which contains the catalyst was used for another run.

\section{General procedure for the Heck cross-coupling reaction}

mTEG-CS-Co-Schiff-base $(0.005 \mathrm{~g}, 0.35 \mathrm{~mol} \%)$ was added to the stirring mixture of aryl halide ( $1 \mathrm{mmol}), \mathrm{Et}_{3} \mathrm{~N}(2 \mathrm{mmol})$, olefine (1.1 $\mathrm{mmol})$ in $\mathrm{H}_{2} \mathrm{O}(3 \mathrm{~mL})$. The above mixture was heated at $90{ }^{\circ} \mathrm{C}$ in an oil bath. The reaction progress was monitored by TLC. After passing the time mentioned in Table 6, the reaction mixture was allowed to be cooled to ambient temperature. The organic compound was extracted with EtOAc $(3 \times 5 \mathrm{~mL})$ from aqueous layer while the catalyst was left in the aqueous phase. The separated organic layer was dried by anhydrous $\mathrm{MgSO}_{4}$ and filtered. The organic solvent was evaporated in vacuum to produce the crude product. The pure products were isolated by chromatography on silica gel ( $n$ hexane:EtOAc $=50: 1)$. The aqueous phase which contains the catalyst was used for another run.

\section{General procedure for the Hirao cross-coupling reaction}

mTEG-CS-Co-Schiff-base $(0.032 \mathrm{~g}, 2 \mathrm{~mol} \%)$ was added to the stirring mixture of aryl halide $(1 \mathrm{mmol}), \mathrm{Et}_{3} \mathrm{~N}(3 \mathrm{mmol})$, triethylphosphite $(2$ $\mathrm{mmol})$ in $\mathrm{H}_{2} \mathrm{O}(4 \mathrm{~mL})$. The above mixture was heated at $80^{\circ} \mathrm{C}$ in an oil bath. The reaction progress was monitored by TLC. After passing the time mentioned in Table 8, the reaction mixture was allowed to be cooled to ambient temperature. The organic compound was extracted with EtOAc $(3 \times 5 \mathrm{~mL})$ from aqueous layer while the catalyst was left in the aqueous phase. The separated organic layer was dried by anhydrous $\mathrm{MgSO}_{4}$ and filtered. The organic solvent was evaporated in vacuum to produce the crude product. The pure products were isolated by chromatography on silica gel ( $n$ hexane:EtOAc = 2:1). The aqueous phase which contains the catalyst was used for another run. 


\section{Conclusion}

In this paper, a new hydrophilic heterogeneous cobalt catalyst of chitosan-Schiff base containing mono-methoxytriethylene glycol (mTEG) as a phase transfer functional group was introduced. This newly synthesized catalyst was characterized by different methods such as XRD, FE-SEM, TEM, TGA, FT-IR, 13C $\{1 \mathrm{H}\}$ CP/MAS NMR, XPS and ICP analysis and used efficiently as a heterogeneous catalyst in $\mathrm{C}-\mathrm{C}$ and $\mathrm{C}\left(\mathrm{sp}^{2}\right)-\mathrm{P}$ cross-coupling reactions such as palladium and fluoride-free Hiyama, Suzuki, Heck and Hirao reactions in water. A wide range of aryliodides, bromides and chlorides (the most challenging arylhalides which are far cheaper and more widely available than aryl iodides and bromides) was coupled successfully with triethoxyphenylsilane, phenylbronic acid, alkyl acrylates, styrene and triethylphosphite to generate the corresponding products. By this method, good to high yields of the products were achieved in water as a benign solvent without the need of any additive or organic solvents. Notably, this is the first report on the application of cobalt catalyst in Hiyama reaction. Any further conversion in the remaining solution after separation of the catalyst in the hot filtration test and poisoning test using $\mathrm{S}_{8}$ showed that the observed catalysis was heterogeneous in nature. Due to the extremely low solubility of the catalyst in organic solvents, the separated aqueous phase which contains the catalyst can be readily recycled for six sequential runs without a noteworthy loss in activity. Finally, the catalyst can be simply isolated from the aqueous layer by filtration. Using water as a green solvent without requiring any additive or organic solvent, low cost and abundant cobalt catalyst instead of expensive $\mathrm{Pd}$ catalysts, facile catalyst recovery and scalability make this method favourable from the environmental and economic point of view for the $\mathrm{C}-\mathrm{C}$ and $\mathrm{C}\left(\mathrm{sp}^{2}\right)-\mathrm{P}$ cross-coupling reactions.

\section{Conflicts of interest}

There are no conflicts to declare.

\section{Acknowledgements}

Financial support of this project by University of Birjand Research Council and Iran National Science Foundation (INSF) and access to the Solid-State NMR facilities at the department of chemistry, Aarhus University and the XPS facilities of University of Alicante are appreciated.

\section{References}

1 a) W. Lee, S. Byun, J. Kwon and B. Moon Kim, Bull. Korean Chem. Soc., 2016, 37, 1992-1997. b) Ch. Torborg and M. Beller, Adv. Synth. Catal., 2009, 351, 3027-3043. c) M. C. Kozlowski, B. J. Morgan and E. C. Linton, Chem. Soc. Rev., 2009, 38, 3193-3207. d) J. Buter, D. Heijnen, C. Vila, V. Hornillos, E. Otten, M. Gianneerini, A. J. Minnaard and B. L. Feringa, Angew. Chem. Int
Ed., 2016, 55, 3620-3624. e) R. Nagarajan, R. F. Pratt, Bio. Chem., 2004, 43, 9664-9673.

2 R. Loska, Ch. M. Volla and P. Vogel, Adv. Synth. Catal., 2008, 350, 2859-2864.

3 W. Li-xia, W. Zi-wei, W. Guo-song, L. Xiao-dong and R. Jian-guo. Polym. Adv. Technol., 2010, 21, 244-249.

4 S. Ma, H.Wang, K. Gao and F. Zhao. J. Mol. Catal. A: Chem., 2006, 248, 17-20.

5 S. Ganesh Babu, N. Neelakandeswari, N. Dharmaraj, S. David Jackson and R. Karvembu. RSC Adv., 2013, 3, 7774-7781.

6 A. Hajipour and Gh. Azizi, Green Chem., 2013, 15, 1030-1034.

7 a) H. Li, L. Xu, J.Ma and Zh. Zhu, ACS Catal., 2012, 2, 2119-2125. b) M. Shao, K. Peng, J. Chen, H. Li, X. Wang, W. Zhang and H. Qi, Catal. Commun., 2009, 10, 1178-1183. c) A. R. Hajipour and Z. Khorsandi, Catal. Commun., 2016, 77, 1-4. d) A. R. Hajipour, F. Rezaei and Z. Khorsandi, Green Chem., 2017, 19, 1353-1361. e) S. Iyer and V. V. Thakur, J. Mol. Catal., 2000, 157, 275-278. f) B. Akhlaghinia and A. Mohammadinezhad, Green Chem., 2017, 19, 5624-5641. g) S. Paul, J. H. Clark, Ch. Sharma, Sh. Sharma and H. Sharma, J. Mol. Catal., 2019, 469, 27-39. h) B. Ramachandra Bhat, L. Mahesh Kumar, Appl. Organomet. Chem., 2017, 827, 4148. i) B. Ramachandra Bhat, R. Ansari, J. Chem. Sci., 2017, 129, 1483-1490. j) B. Ramachandra Bhat, A. Saroja, Ind. Eng. Chem. Res., 2019, 58, 590-601. k) B. R. Bhat, L. M. Kumar, R. M. Ansari, Russ. J. Coord. Chem., 2018, 44, 1-8. I) T. Ghosh, P. Maity, D. Kunda and B. C. Ranu, New J. Chem., 2016, 40, 9556-9564.

8 a) J. Bao, J. Zhou, P. Sun, Y. Li and P. Zho, Chem. Commun., 2007, 1418-142. b) I. W. Davies, L. Matty, D. L. Hughes. J. Am. Chem. Soc., 2001, 123, 10139-10140. c) M. Nasrollahzade and S. M. Sajadi, J. Colloid Interface. Sci., 2016, 465, 121-127. d) A. Modak and A. Bhaumik, J. Mol. Catal A. Chem., 2016, 425, 147-156.

9 a) V. Calo, A. Nacci, A. Monopoli. J. Organomet. Chem., 2005, 690, 5458-5466. b) M. Rinaudo, Prog. Polym. Sci., 2006, 31, 603632.

10 D. J. Macquarrie and J. J. E. Hardy, Ind. Eng. Chem. Res., 2005, 44, 8499-8520.

11 a) N. V. Majeti and R. Kumar, React. Funct. Polym., 2000, 46, 127. b) T. A. Ahmed and B. M. Aljaeid, Drug Des. Devel. Ther., 2016, 10, 483-507. c) J. Desbrieres and E. Guibal, Polym. Int., 2018, 67, 7-14. d) G. Yuan, X. Chen and D. Li, Food Res. Int., 2016, 89, 117-128. e) A. Verlee, S. Mincke and Ch. V. Stevens, Carbohyd. Polym., 2017, 164, 268-283.

12 a) W. Lia-xia, W. Zi-wei, W. Guo-song, L. Xiao-dong and R. Jianguo, Polym. Adv. Technol. 2010, 21, 244-249. b) S. M. Alshehri, T. Almuqati, N. Almuqati, E. Al-Farraj, N. Alhokbany, T. Ahmad, Carbohydr. Polym., 2016, 151, 135-143. c) M. Sarvestani and R. Azadi, Appl. Organomet. Chem., 2017, 32, 3906-3915. d) A. Fakhri and A. Naghipour, Comments Inorg. Chem., 2017, 37, 201-218. e) Kh. Khalili and H.M. Al-Matar, Molecules 2013, 18, 5288-5305. f) M. Zeng, X. Yuan, Sh. Zuo and Ch. Qi, RSC Adv., 2015, 5, 37995-38000. g) B. Yang, Z. Mao, X. Zhu and Y. Wan, Catal. Commun., 2015, 60, 92-95.

13 a) J. Tong, Zh. Li and Ch. Xia, J. Mol. Catal. A-Chem., 2005, 231, 197-203. b) L. Shao, G. Xing and Ch. Qi, Cellulose 2019, 26, 6769- 
6783. c) C. Thatte, M. Rathnam and A. Pice, J. Chem. Sci., 2014, 126, 727-737. d) R. Antony, S. T. D. Manickam, K. Saravanan, K. Karuppasamy and S. Balakumar, J. Mol. Struct., 2013, 1050, 5360.

14 M. Guo, Sh. Liu, X. Zhou, M. Lv, S. Chen and D. Xiao, Molecules, 2014, 19, 6524-6533.

15 a) S. Sobhani, Z. Pakdin-Parizi and R. Nasseri, J. Chem. Sci., 2013, 125, 975-979, b) S. Sobhani and F. Zarifi, RSC Adv., 2015, 5, 95532-95538. c) S. Sobhani, Z. Mesbah Falatooni and M. Honarmand, RSC Adv., 2014, 4, 15797-15806. d) S. Sobhani, F. Omarzehi Chahkamali, J. Miguel Sansano, RSC Adv., 2019, 9, 1362-1372.

16 B. Huang, J. Chen, Sh. Zhan and J. Ye, J. Electrochem. Soc., 2016, 163, G26-G32.

17 T. Paranhaman, N. Pentela, B. Ramalingam, D. Samanta and S. Dos, ACS Sustain. Chem. Eng., 2017, 5, 489-501.

18 X. Cai, H. Wang, Q. Zhang, J. Tong and Z. Lei, J. Mol. Catal AChem., 2014, 383, 217-224.

19 A. R. Hajipour and P. Abolfathi, Catal. Commun., 2018, 103, 9295.

20 Y. Hatanaka and T. Hiyama, J. Org. Chem., 1988, 53, 918-920.

21 a) K. Tamao, K. Sumitani, M. Kumada, J. Am. Chem. Soc. 1972, 94, 4374-4376. b) E. Negishi, Acc. Chem. Res., 1982, 15, 340348.

22 A. Suzuki, J. Organomet. Chem., 1999, 576, 147-168.

23 Sh. Shi and Y. Zhang, J. Org. Chem., 2007, 72, 5927-5930.

24 a) S. Sobhani, M. Sadat Ghasemzadeh, M. Honarmand and F. Zarifi, RSC Adv., 2014, 4, 44166-44174. b) S. Sobahni, Z. Zeraatkar and F. Zarifi, New J. Chem., 2015, 39, 7076-7085. c) S. Sobahni, Z. Mesbah Falatooni, S. Asadi and M. Honarmand, Catal. Lett., 2016, 146, 255-268. d) S. Sobhani and F. Zarifi, Chinese J. Catal., 2015, 36, 555-563. e) S. Sobhani, A. Habibollahi, Z. Zeraatkar, Org. Process Res. Dev., 2019, 23, 1321-1332.

25 B. Akhlaghinia and M. Zarghani, Bull. Chem. Soc. Jpn. 2016, 89, 1192-1200.

26 T. Baumgartner and R. Reau, Chem. Rev., 2006, 106, 4681-4727.

27 F. R. Fronezek, R. L. Luck and G. Wang, Inorg. Chem. Commun., 2002, 5, 384-387.

28 Q. Lin, S. Unal, A. R. Fornof, R. S. Armentrout and T. Long, Polymer, 2006, 47, 4085-4093.

29 T. Bock, H. Mohwald and R. Mulhaupt, Macromol. Chem. Phys., 2007, 208, 1324-1340.

30 C. R. Samanamu, E. N. Zamora, J. Montchamp and A. F. Richards, J. Solid State Chem., 2008, 181, 1462-1471.

31 K. D. Belfield, C. Chinna and K. J. Schafer, Tetrahedron Lett., 1997, 38, 6131-6134.

32 S. M. Zakeeruddin, M. K. Nazeeruddin, P. Pechy, F. P. Rotzinger, R. Humphry-Baker, K. Kalyanasundaram, M. Gratzel, V. Shklover and T. Haibach, Inorg. Chem., 1997, 36, 5937-5946.

33 T. Hirao, T. Masunaga, Y. Ohshiro and T. Agawa, Synthesis, 1981, 01, 56-57.

34 a) M. Kalek, M. Jezowska and J. Stawinski, Adv. Synth. Catal., 2009, 351, 3207-3216. b) R. Berrino, S. Cacchi, G. Fabrizi, A. Goggiamani and P. Stabile, Org. Biomol. Chem., 2010, 8, 4518- 4520.c) S. Y. Chen, R. S. Zeng, J. P. Zou and O. T. Asekun, J. Org Chem., 2014, 79, 1449-1453. d) G. Hu, W. Chen, T. Fu, Z. Peng, H. Qiao, Y. Gao and Y. Zhao, Org. Lett., 2013, 15, 5362-5365. e) W. C. Fu, C. M. So and F. Y. Kwong, Org. Lett., 2015, 17, 5906-5909.

35 O. Berger, C. Petit, E. L. Deal and J.-L. Montchamp, Adv. Synth. Catal., 2013, 355, 1361-1373.

36 D. Van Allen and D. Venkataraman, J. Org. Chem., 2003, 68, 4590-4593.

37 X. -J. Mu, J. -P. Zou, Q. -F. Qian and W. Zhang, Org. Lett., 2006, 8, 5291-5293.

38 C. Shen, G. Yang and W. Zhang, Org. Biomol. Chem., 2012, 10, 3500-3505.

39 Y. He, H. Wu and F. D. Toste, Chem. Sci., 2015, 6, 1194-1198.

40 G. Hu, W. Chen, D. Ma, Y. Zhang, P. Xu, Y. Gao and Y. Zhao, J. Org. Chem., 2016, 81, 2680-2680.

41 a) W. Affo, H. Ohmiya, T. Fujioka, Y. Ikeda, T. Nakamura, H. Yorimitsu, K. Oshima, Y. Imamura, T. Mizuta and K. Miyoshi, J. Am. Chem. Soc., 2006, 128, 8068-8077. b) S. Maity, P. Dolui, R. Kancherla and D. Maiti, Chem. Sci., 2017, 8, 5181-5185. c) M. E. Weiss, L. M. Kreis, A. Lauber and E. M. Carreira, Angew. Chem. Int. Ed., 2011, 50, 11125-11128. d) M. Kazemnejadi, S. A. Alavi G, Z. Rezazadeh, M. A. Nasseri, A. Allahresani and M. Esmaeilpour, Green Chem., 2019, 21, 1718-1734.

42 V. Percec and D. Tomazos, J. Mater. Chem. 1993, 3, 633-642.

43 B. Yuan, L Gan Qiu, H. Zhen Su, Ch. liang Cao and J. hong Jiang, Int. J. Biol. Macromol., 2016, 82, 355-360. 